
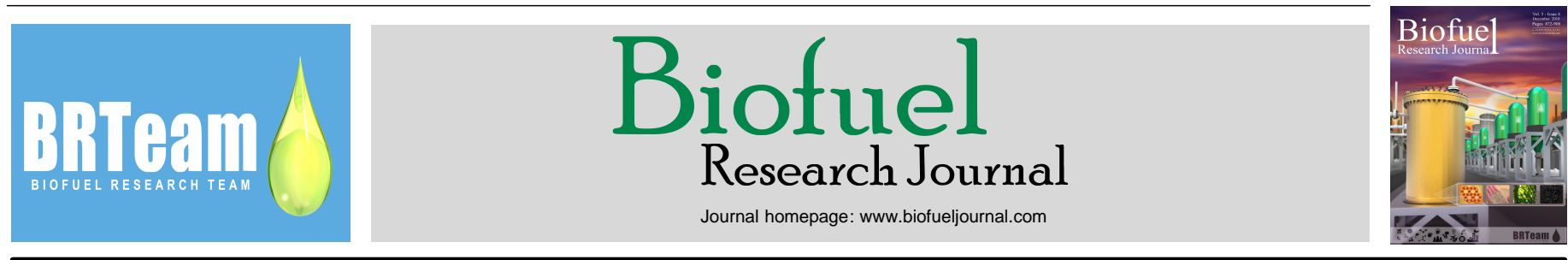

Original Research Paper

\title{
First-order estimates of the costs, input-output energy analysis, and energy returns on investment of conventional and emerging biofuels feedstocks
}

\author{
Katrina Christiansen ${ }^{1, *}$, David Raj Raman ${ }^{2}$, Guiping $\mathrm{Hu}^{3}$, Robert Anex ${ }^{4}$
}

${ }^{1}$ Stalende, LLC $3104^{\text {th }}$ Ave SE Jamestown, ND 58401, USA.

${ }^{2}$ Department of Agricultural and Biosystems Engineering, Iowa State University, Ames, IA 50011, USA.

${ }^{3}$ Department of Industrial and Manufacturing Systems Engineering, Iowa State University, Ames, IA, 50011, USA.

${ }^{4}$ Department of Biological Systems Engineering, University of Wisconsin, Madison, WI, USA.

\section{HIGHLIGHTS}

$>$ Compared fuel production metrics from various biomass feedstocks.

$>$ Estimated the carbon equivalent emissions associated with biofuel produciton.

$>$ Predicted algae biomass production rates of 120 $\mathrm{MG} /$ (ha a), ten times greater than Maize.

$>$ Predicted algae biofuel costs ranging from 28 to 65 US \$/GJ compared to 17 US $\$ /$ GJ for Maize ethanol. $>$ Estimated biofuel energy returns on investment near zero for algae and 25 for Switchgrass.

\section{ARTICLE INFO}

\section{Article history:}

Received 31 July 2018

Received in revised form 28 September 2018

Accepted 8 October 2018

Available online 1 December 2018

\section{Keywords:}

Algae

Biofuel

Biomass feedstocks

Bioenergy

LCA

Input-output analysis

\section{GRAPHICAL ABSTRACT}

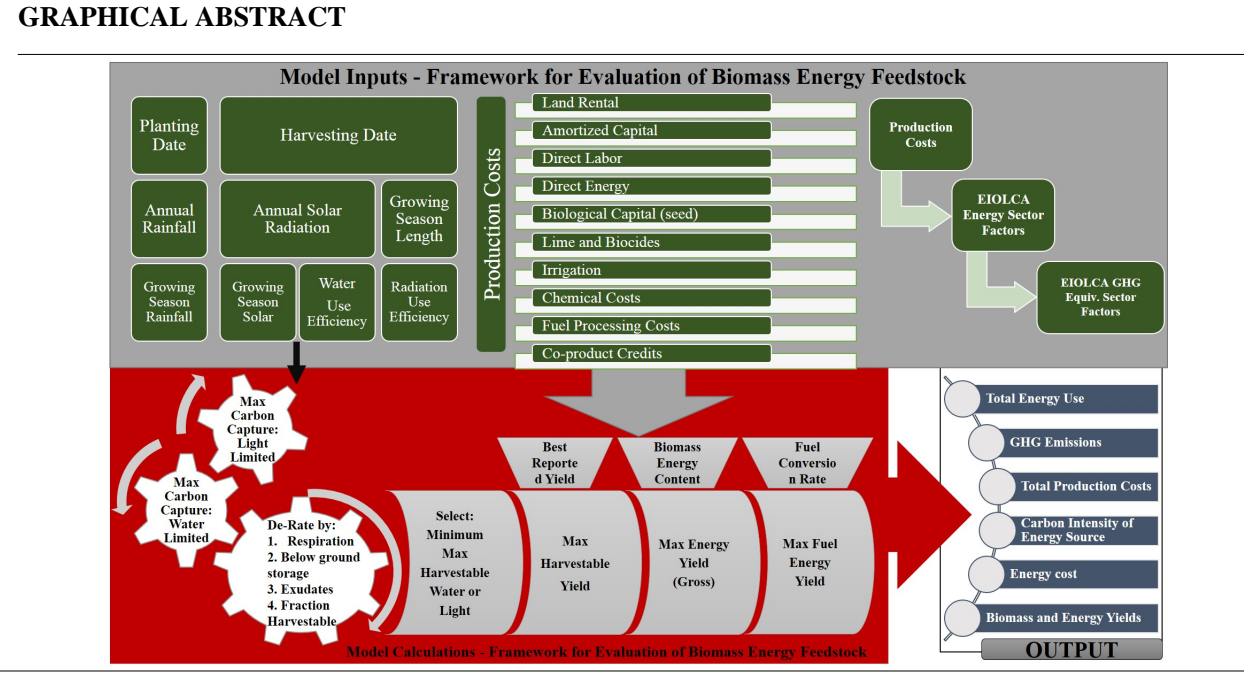

\begin{abstract}
Here we report on a static, algebraic, spreadsheet-implemented modeling approach to estimate the costs, energy inputs and outputs, and global warming potential of biomass feedstocks. Inputs to the model included literature sourced data for: environmental factors, crop physiological-parameters such as radiation use efficiency and water use efficiency, and crop cost components. Using an energy-input-output life-cycle-assessment approach, we calculated the energy associated with each cost component, allowing an estimate of the total energy required to produce the crop and fuel alongside the energy return on investment. We did this for crop scenarios in the upper Midwest US and Far West US (for algae). Our results suggested that algae are capable of the highest areal biomass production rates of $120 \mathrm{MG} /(\mathrm{ha} \cdot \mathrm{a})$, ten times greater than Maize. Algal fuel systems had the highest costs, ranging from 28 to 65 US \$/GJ, compared to 17 US \$/GJ for Maize ethanol. Algal fuel systems had the lowest energy returns on investment, nearly 0, compared to 25 for Switchgrass to ethanol. The carbon equivalent emissions associated with the production schemes predictions ranged from 40 (Maize) to 180 (algae PBR) $\mathrm{CO}_{2 \mathrm{eq}} / \mathrm{GJ}_{\text {net. }}$. The promise of low cost fuel and carbon neutrality from algae is demonstrated here to be extremely challenging for fundamental reasons related to the capital-intensive nature of the cultivation system.
\end{abstract}

* Corresponding author at: Tel.: +1 5154510859

E-mail address: katrina.christiansen@stralendellc.com

Please cite this article as: Christiansen K., Raman D.R., Hu G., Anex R. First-order estimates of the costs, input-output energy analysis, and energy returns on investment of conventional and emerging biorenewable feedstocks. Biofuel Research Journal 20 (2018) 894-899. DOI: 10.18331/BRJ2018.5.4.4 


\begin{tabular}{|ll|}
\hline Abbreviations & \\
AZ & Arizona \\
bbl & Barrel \\
BRY & Best Reported Yield \\
CC & Cost of Conversion \\
CCFEP & Cost for Conversion of Fuel Energy Produced \\
CFEP & Cost for Fuel Energy Produced \\
CIES & Carbon Intensity of Energy Source \\
CIFES & Carbon Intensity of Fuel Energy Source \\
CO 2 eq & Carbon Dioxide Equivalent \\
EC & Energy Cost \\
ECB & Energy Content Of Biodiesel \\
EIO-LCA & Economic Input-Output Life Cycle Assessment \\
EROI & Energy Return on Investment \\
FEBEF & Framework for the Evaluation of Biomass Energy \\
HI & Feedstocks \\
GHG & Haiwaii \\
MFEY & Greenhouse Gas \\
MG & Maximum Fuel Energy Yield-Net Converted \\
MHY & Megagram \\
NM & Maximum Harvestable Yield \\
ORP & New Mexico \\
PAR & Open Raceway Pond \\
PBR & Photosynthetically Available Radiation \\
PV & Photobioreactors \\
RMHY & Photovoltaic \\
RUE & Ratio of Max Light to Max Water Yields \\
TCFEP & Radiation Use Efficiency \\
TCP & Total Cost for Fuel Energy Produced \\
TEC & Total Cost for Production \\
TEU & Total Energy Cost \\
TEUC & Total Energy Use \\
TEUP & Total Energy Use for Conversion \\
TEUPC & Total Energy Use for Production \\
TFEO & Total Energy Use for Production and Conversion \\
TFEY & Transportation Fuel Energy Out \\
WUE & Total Fuel Energy Yield \\
& Water Use Efficiency \\
& \\
& \\
&
\end{tabular}

\section{Introduction}

Photosynthetically-derived carbon will provide critical material and energy resources for humanity in the $21^{\text {st }}$ century, and beyond. Furthermore, barring catastrophes, the demand for these resources will rise as human populations increase, standards of living increase, and non-renewable (i.e., fossil) carbon sources are depleted. The environmentally-sustainable and cost-effective production of biorenewable carbon is therefore one of several defining challenges for our species in this century. Tackling this challenge will involve an array of approaches including developing novel plants and cropping systems and optimizing landscape design to meet human needs, and will be facilitated by robust estimates of the cost, energy requirements, and environmental impacts of various biomass resources are critical.

The scientific consensus that anthropogenic global warming is occurring (Carlton et al., 2015; Cook et al., 2016) has driven a multitude of approaches to reducing the carbon-intensity of modern industrial society (Leung et al., 2014; Huisingh et al., 2016). Although the likelihood is low that these approaches, even collectively, can stave off major climate changes that will severely impact existing global agricultural production (Schuur et al., 2008; Gornall et al., 2010; Jaggard et al., 2010; Lesk et al., 2016), such approaches are still worthy of exploration as they can be part of an effort to reduce the degree of warming that ultimately occurs (Pacala, et al., 2004). One existing yet controversial approach (Keyzer et al., 2008; Tomei and Helliwell, 2016) to reducing anthropogenic greenhouse gas emissions is by replacing fossil-based liquid transportation fuels (primarily gasoline and diesel) with similar or identical fuels derived from biomass resources (Wang, 1999; Richard, 2010). Brazil makes $22 \%$ of its transportation energy from sugarcane-derived ethanol - totaling approximately $31 \times 10^{9} \mathrm{~L}$ annually (FAO, 2015) - while the US makes over $13 \%$ of its gasoline volume from Maize-starch-derived ethanol - totaling approximately $56 \times 10^{9} \mathrm{~L}$ annually (EIA, 2016). The economic and environmental viability of these biofuels have been questioned for at least the last two decades (Hill et al., 2006; Gomiero et al., 2015), with concerns on issues such as competition between human food and vehicle fuel needs, water quality impacts of increasingly intensive management practices, and air quality and wildlife habitat impacts from changing landuse patterns (Hill et al., 2016; Otto et al., 2016). In addition to a strong debate on these claims in the scientific literature, some have sought to address the weaknesses of starch-ethanol by developing biofuel production systems that convert into fuel the lignocellulosic portion of Maize, or the lignocellulosic biomass derived from perennial crops, or the oil and lignocellulosic biomass formed by microalgae (Pienkos and Darzins, 2009). This plethora of approaches to biofuel production has made it difficult to understand the fundamental performance of and barriers to these different feedstocks. The purpose of this study was to use a generalized modeling approach to provide insight into the strengths and weaknesses of these potential technologies.

\section{Materials and Methods}

The model implements an algebraic, static, approach to estimating productivity and cost of biomass feedstocks detailed in the model available here (https://works.bepress.com/raj_raman/64/). The overall computational approach for any feedstock is the same and is as follows: Compute a solarenergy-limited maximum carbon-capture based upon growing-season solar energy inputs and literature reported radiation use efficiency (RUE). In parallel, compute a water-limited maximum carbon-capture based upon growing-season rainfall and literature reported maximum water use efficiency (WUE). De-rate both maximum carbon-capture estimates to account for critical losses including respiration and non-harvestable fraction, to estimate a maximum light-limited and water-limited yield select the lower of the two to estimate the maximum biomass yield. Use the maximum biomass yield to calculate theoretical energy yield based on biomass energy content, as well as maximum biofuel yields based upon literature estimates of conversion efficiencies from biomass to fuel. The Supplementary Methodology "Framework for the Evaluation of Biomass Energy Feedstocks (FEBEF)" describes the calculations in detail.

To estimate costs, the FEBEF divides the cost of production and fuel conversion into nine primary line-items that are inclusive of both terrestria and aquatic feedstocks, namely: land rental, amortized capital, direct labor, direct energy, biological capital, macronutrients, lime and biocides, irrigation, and carbon dioxide. These costs are expressed on a per unit land area basis, as literature estimates inform their values. All costs except algae capital costs scale by yield to reflect that higher yield typically requires more inputs and occurs on higher value land (e.g., Clark et al., 1999; Lobell et al., 2009). Algae capital costs scale by area rather than yield.

The model uses an economic-input-output-life-cycle-analysis approach to compute the embedded energy and greenhouse-gas emissions from each cost line-item (Carnegie Mellon University Green Design Institute, 2008) in 2015 dollars customized for Iowa. The sum of these allows a first-order estimate of the total embedded energy as well as of the greenhouse gas (GHG) emission associated with feedstock production.

With maximum yield, biomass cost, energy input, and GHG emissions available for each feedstock, FEBEF computes key performance indicators such as: Gross Maximum Energy Yield (GJ/(ha-a)), Energy Return on Investment (EROI, dimensionless), and Biomass Production Cost (US $\$ /$ ton, US $\$ / \mathrm{Mg}$ ). Furthermore, based upon the biomass-to-fuel conversion parameters, FEBEF computes other additional key performance indicators including Net Maximum Fuel Energy Yield (GJ/(ha·a)), Fuel Energy Cost (US $\$ / G J)$, and Carbon Intensity of Fuel Energy Source $\left(\mathrm{kg} \mathrm{CO}_{2 \text { eq }} / \mathrm{GJ}\right)$. A summary of the computations and categories is given Table 1 .

\section{Results and Discussion}

\subsection{Model biomass outputs}

The model Maximum Harvested Yields (MHY) as predicted by radiation or water use limited computation are shown in Figure 1 and compared to 
Table 1.

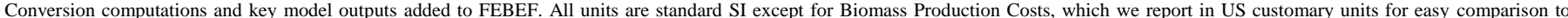

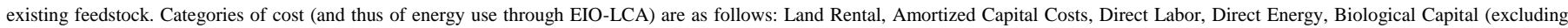

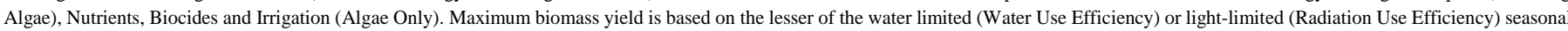

\begin{tabular}{|c|c|c|c|}
\hline Output & Computation & Units & Abbreviation \\
\hline Maximum Harvestable Yield & Maximum Seasonal Biomass Yield multiplied by Harvestable Fraction & $\mathrm{Mg} /(\mathrm{ha} \cdot \mathrm{a})$ & MHY \\
\hline Biomass Energy Content & Higher Heating Value in Literature & $\mathrm{MJ} / \mathrm{kg}$ & BEC \\
\hline Total Production Cost & Sum of all categorical production costs & US $\$ /($ ha $\cdot a)$ & TPC \\
\hline Total Energy Use-Production & Sum of energies from EIO-LCA applied to each category of production costs & $\mathrm{GJ} /(\mathrm{ha} \cdot \mathrm{a})$ & TEP \\
\hline Maximum Energy Yield Gross & MHY $\times$ BEC & $\mathrm{GJ} /(\mathrm{ha} \cdot \mathrm{a})$ & $\mathrm{MEY}_{\mathrm{G}}$ \\
\hline Maximum Energy Yield, Net & MEY $_{\mathrm{G}}-\mathrm{TEP}$ & $\mathrm{GJ} /(\mathrm{ha} \cdot \mathrm{a})$ & $\mathrm{MEY}_{\mathrm{N}}$ \\
\hline Energy Return on Investment & $\mathrm{MEY}_{\mathrm{G}} / \mathrm{TEP}$ & Dimensionless & EROI \\
\hline Biomass Production Cost & TPC/MHY & US \$/ton & BPC \\
\hline Energy Production Cost & $\mathrm{TPC}_{\mathrm{MEY}} \mathrm{G}$ & US \$/GJ & $\mathrm{EPC}$ \\
\hline $\begin{array}{l}\text { Total Fuel Energy Yield (Ethanol for terrestrial crops, } \\
\text { Biodiesel for algae) }\end{array}$ & Fuel Converted Yield $\times$ Fuel Energy Content & $\mathrm{GJ} /($ ha·a) & TFE \\
\hline Green House Gas Emissions-Areal (Biomass only) & $\begin{array}{l}\text { (Greenhouse Gas emission Indirect (literature) + Greenhouse Gas emission Direct } \\
\text { (EIO-LCA)) }\end{array}$ & $\mathrm{kg} \mathrm{CO}_{2 \text { eq }} /(\mathrm{ha} \cdot \mathrm{a})$ & GHG-ArealB \\
\hline GHG Intensity (Biomass only) & GHG-Areal / Total Fuel Energy Yield & $\mathrm{kg} \mathrm{CO}_{2 \mathrm{eq}} / \mathrm{GJ}$ & GHG-Intensity \\
\hline Total Energy Use Fuel Conversion & Sum of Energy Use in Fuel Conversion & $\mathrm{GJ} /(\mathrm{ha} \cdot \mathrm{a})$ & TEF \\
\hline Total Energy Use & $\mathrm{TEP}+\mathrm{TEF}$ & $\mathrm{GJ} /(\mathrm{ha} \cdot \mathrm{a})$ & TEU \\
\hline Transportation Fuel Energy Out & TFE/MHY & $\mathrm{GJ}_{\text {out }} / \mathrm{Mg}$ Biomass & TFEO \\
\hline Maximum Fuel Energy Yield-Net Converted & TFE - TEU & $\mathrm{GJ} /(\mathrm{ha} \cdot \mathrm{a})$ & $\mathrm{MFEY}_{\mathrm{NC}}$ \\
\hline $\begin{array}{l}\text { Maximum Fuel Energy Yield-Net Converted with Co-Product } \\
\text { Credit }\end{array}$ & $\mathrm{MFEY}_{\mathrm{NC}}+$ Co-product Credit & $\mathrm{GJ} /(\mathrm{ha} \cdot \mathrm{a})$ & $\mathrm{MFEY}_{\mathrm{NC}-\mathrm{CCP}}$ \\
\hline Biofuel Energy Return on Investment without Co-Product Credit & $\mathrm{MFEY}_{\mathrm{NC}} / \mathrm{TEU}$ & dimensionless & $\mathrm{EROI}_{\mathrm{B}}$ \\
\hline Energy Return on Investment with Co-Product Credit & $\mathrm{MFEY}_{\mathrm{NCCP}} / \mathrm{TEU}$ & dimensionless & $\mathrm{EROI}_{\mathrm{CPC}}$ \\
\hline Fuel Energy Cost & $(\mathrm{BPC}+\mathrm{FPC}) / \mathrm{TFE}$ & US \$/GJ & FPC \\
\hline GHG Total-Areal Basis & $\begin{array}{l}\text { Conversion Indirect Emissions + Conversion Direct Emissions + GHG-Areal } \\
\text { Basis }\end{array}$ & $\mathrm{kg} \mathrm{CO}_{2 \mathrm{eq}} /(\mathrm{ha} \cdot \mathrm{a})$ & GHGT $_{\mathrm{AB}}$ \\
\hline Carbon Intensity of Fuel Energy Source & $\mathrm{GHGT}_{\mathrm{AB}} / \mathrm{MEY}_{\mathrm{N}}$ & $\mathrm{kg} \mathrm{CO}_{2} \mathrm{eq} / \mathrm{GJ}$ & CIFES \\
\hline
\end{tabular}

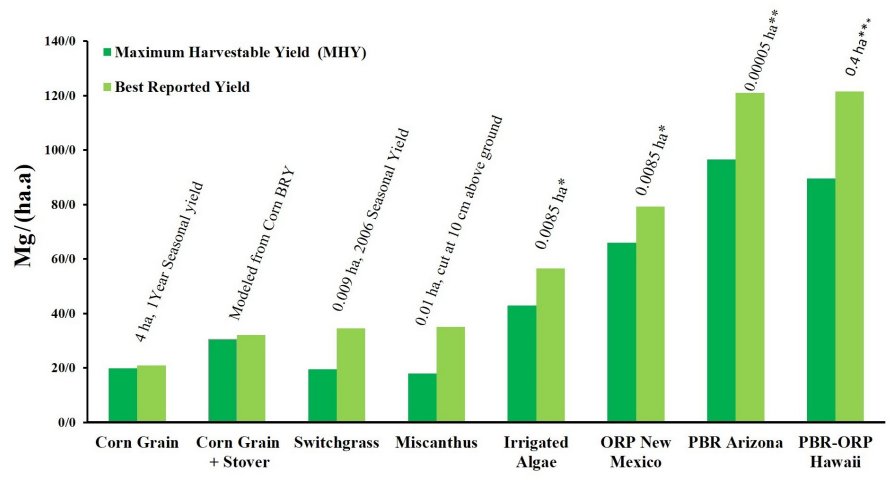

Fig. 1. The model estimates of maximum harvestable yield (MHY, $\mathrm{Mg} /($ ha.a)) for each of the seven systems is shown as dark bars alongside the best reported yields (BRY, $\mathrm{Mg} /($ ha.a)) for the same case (light bars). Approximate collection areas and durations of the BRY values are provided for context $(*$ : Extrapolated from 2-Yeat Seasonal Average; **: Extrapolated from daily maximum; ***: Extrapolated from historic maximum)

Best Reported Yields (BRY) from literature. In many cases, the model appears conservative with slightly higher yields reported than predicted.
In contrast, when considering large-area averages, actual yields are predictably lower, for example, the 2015 Maize grain yield was $12 \mathrm{Mg} / \mathrm{ha}$ in Iowa and $10.5 \mathrm{Mg} / \mathrm{ha}$ in the US overall, or roughly half the maximum predicted. But the US overall yield reflects performance over some 32.6 $\times 10^{6}$ ha of cropland. The claims by algal fuel proponents regarding the superior yield potential is supported by the best-reported yields and the model predicted MHY. Continuous yield data sets from commercial or large research scale production are scarce for algae as well as for Switchgrass and Miscanthus, they were therefore extrapolated from shortterm and/or small-scale results for comparison. As reflected in the divergence between large-scale and small plot Maize yields, caution should be used in presuming that such yields could actually be realized at present in full-scale systems. Algal production systems have the advantage of continuous harvest and production, as well as of not leaving inaccessible (non-harvestable) biomass underground. This drives their impressive areal biomass annual yields, which are more than double the terrestrial crops. Furthermore, our results suggest that algae are RUE limited, in contrast to the non-irrigated terrestrial crops we modeled which are WUE limited. Maize, however, has lower respiration carbon losses (20\%) (Taylor, 1998) than algae, (25\%) (Christi, 2007). All the terrestrial crops invest carbon in unharvested root biomass, lose carbon to soil through root exudates, and also have an unharvested biomass above ground. All these biological, agricultural, and mechanical differences lead to huge calculated differences in the total fixed carbohydrate by the plants; Algae fixing $71 \%$, Maize (Grain) 35\%, Maize (Grain +Stover) 53\%, Switchgrass 34\%, and 
Miscanthus $27 \%$. These processes and practices lead to the biomass yield advantage carried by algae.

Interestingly, Maize grain plus stover outperforms the other cellulosic crops. For terrestrial crop yields to approach the BRYs on a broad scale, growers would have to replicate the intensive farming practices done at the small scale while the algal production would have to overcome the challenges of exponential growth and lag phase cycles to maintain high yield consistently on an annual basis.

\subsection{Annual energy production (raw biomass)}

Combining the yield data with assumptions regarding biomass energy density results is an estimate of the annual gross energy production for each system. To contextualize these values, the values are also expressed on the basis of percentage of total annual site solar radiation collected as shown in Figure 2. The gross energy yield tracks closely to the relative energy capture (ratio of energy capture $\mathrm{GJ} /(\mathrm{ha} \cdot \mathrm{a})$ to solar radiation $\mathrm{GJ} /(\mathrm{ha} \cdot \mathrm{a})$ ) for all production scenarios. The benefit of an extended production season with the three southern algal production scenarios as well as being photosynthetically limited in carbon capture lead to the marked differential in energy yield with the terrestrial crops. In contrast are the biomass production costs, it is far more expensive to make biomass in aquatic schemes than terrestrial as shown in Figure 3. Aquatic systems have large capital costs as well as high labor costs and direct energy costs for centrifugation and cooling. The photobioreactor (PBR) system much more so, resulting in biomass production costs tens time more than the terrestrial and double the other algal scenarios.

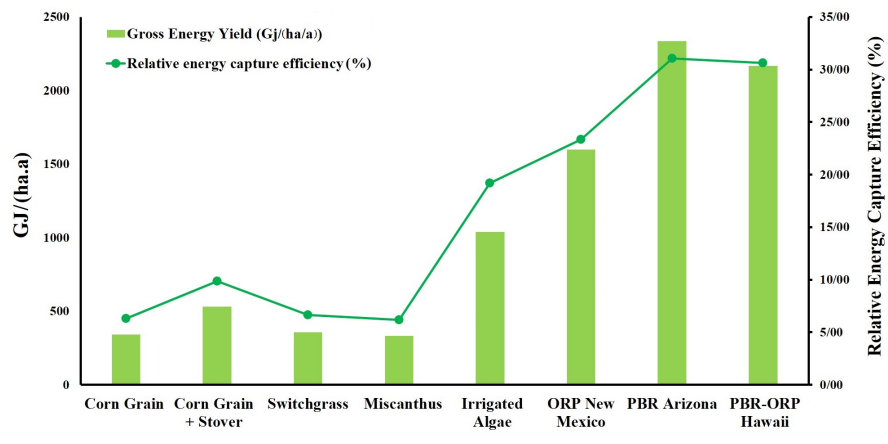

Fig. 2. Gross Energy Production Yield (GJ/(ha.a)) and Relative Energy Capture Efficiency (\%).

These algae biomass production values are lower than the minimum selling price reported in the Billion Ton report (719-2998 US \$/dry ton) (US DOE, 2016). The lowest cost production crop, Switchgrass, is due mostly to the lower land rental costs associated with marginal land in addition to being a perennial. The biomass production costs between the perennial crops are $30 \%$ to $45 \%$ lower than the annual Maize crop. While there is an established stand cost advantage for perennial crops, there is also the risk the growers assume by delaying planting of a genetically improved crop every year as one can do with Maize.

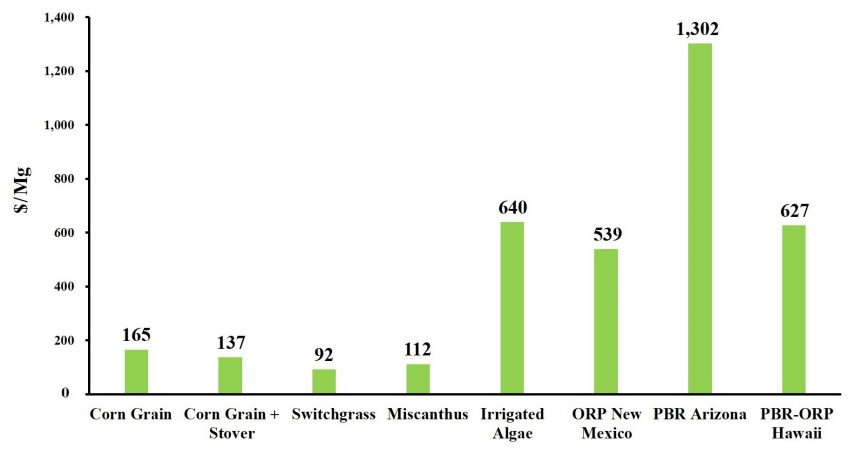

Fig. 3. Biomass production costs for the terrestrial and algal production scenarios.

It is important for bioenergy proponents to be cognizant of the constantly increasing efficiency of photovoltaic (PV) cells. These systems have seen a $0.3 \%$ annual increase in efficiency (Detwiler, 2013) with disruptive technologies leading to huge increase of $7 \%$ efficiency (Mearian, 2015) over current commercial cells, much greater than the $1 \%$ annual rate of yield increase of Maize (Neilsen, 2012). Furthermore, commercially available PV are now achieving efficiencies ca. $25 \%$, which is greater than all but the algal systems we modeled. Moreover, while all practical energy systems are subject to various storage, transport, and conversion losses, from a vehicle-propulsion standpoint, PV-based electric vehicles have a significant advantage, as shown in Table 2.

As tabulated in Table 2, current PV systems can achieve photon-towheel efficiencies on the order of $20 \%$. This is over seven times greater than the best widely commercially available scenario for biofuel. At present, no rechargeable battery comes within an order of magnitude of the energy density achieved by ethanol or biodiesel. The benefits of such high energy densities are diminishing for surface vehicles, as increasing efficiency leads to reduced total energy storage needs, and improved materials lead to ever lighter structures which "make room" for heavier energy storage systems. But in long-haul aviation, the benefits of high energy density are harder to overcome, thus justifying the strategy of aviation-biofuels.

While the fuel conversion costs of oil to biodiesel are less than for lignocellulosic biomass to ethanol, the total energy cost for algal biofuels systems is still greater than that for terrestrial crops biofuels, as shown in Figure 4. Algal fuel technologies suffer from both high capital and operating costs. The impact of marginal land costs, lower crop inputs and water use efficiencies drive the low cost energy option to be Switchgrass. However, the cost of conversion for the lignocellulosic crops pushes the total energy cost for Switchgrass above that of Maize. This is not surprising and tracks the experience of the US ethanol industry in which slightly over $200 \mathrm{starch} / \mathrm{sugar}$ ethanol plants currently produce 15.7 billion gallons of ethanol annually, while 15 cellulosic plants produce a total of $0.1 \mathrm{~B}$ gallons annually (Ethanol Producer Magazine, 2018). This 150-fold volume

Table 2.

Photon to wheel efficiencies for selected crops, as well as for photovoltaic-supplied battery electric vehicles. (Source: http://www.cleancaroptions.com/html/energy_efficiency.html)

\begin{tabular}{|c|c|c|c|c|}
\hline System & Photon-Fuel Efficiency (\%) & Fuel-Wheel Efficiency (\%) & Overall Efficiency (Photon-Wheel) (\%) & Fuel Energy Density (MJ/kg) \\
\hline Maize Grain to Gas ICE & 7 & 23 & 1.6 & 26.4 \\
\hline Maize Grain to Hybr. ICE & 7 & 40 & 2.8 & 26.4 \\
\hline Maize Grain + Stover to Gas ICE & 10 & 23 & 2.3 & 26.4 \\
\hline Maize Grain + Stover to Hybr. ICE & 10 & 40 & 4.0 & 26.4 \\
\hline Best-Case Algae to Gas ICE & 30 & 23 & 6.9 & 42.2 \\
\hline Best-Case Algae to Hybr. ICE & 30 & 40 & 12.0 & 42.2 \\
\hline Photovoltaic to BEV & 25 & 85 & 21.3 & $\sim 1.0$ \\
\hline
\end{tabular}




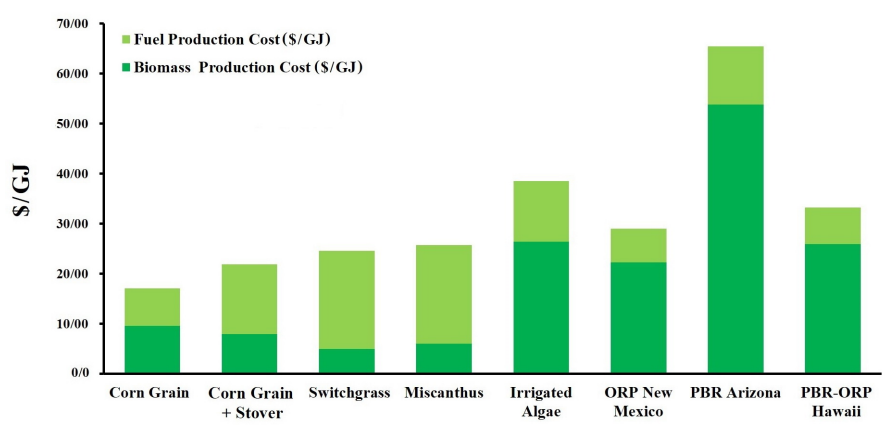

Fig. 4. Total Energy Production Costs $(\$ / \mathrm{GJ})$ summed from biomass production cost and fuel production cost. Dark horizontal vertical line at left to range of gasoline prices (pre-tax) from 2012 - 2018 projected (Source: EIA 2018; https://www.eia.gov/outlooks/steo/report/us_oil.cfm).

difference is significant and serves as an industrial indicator of biological challenges of degrading cellulose and lignin into fermentable sugars. While there have been technological advancements made in the conversion of cellulose to ethanol (Singh et al., 2015), there has yet to be a disruptive technology that halves the cost of conversion in tandem with reducing the cost of transporting lower energy dense, cellulosic feedstock to plants at larger radii (Hess, 2007). The cost of fuel from algae is not cost competitive with the ethanol feedstocks due to the high capital and labor costs even though the cost of biodiesel conversion is less than Maize ethanol. Predicted algal fuel costs are $30 \%$ more than the terrestrial crop fuels even though there is 1.5 times more energy density in biodiesel than ethanol. The low cost of ethanol from Switchgrass is due to the low production costs. It is difficult for ethanol and biodiesel to compete in the fuel market until oil exceeds a variable breakeven point (US \$/bbl) given the dependencies of crude oil, gasoline, ethanol, corn, and Distiller Grains prices alongside oxygenate premiums and government subsidies.

When we examine the energy production cost for algal systems as function of interest rate on the capital, we see that there is a meaningful increase from $0 \%$ interest to $5 \%$ and then $10 \%$. The internal rate of return and discount rate of $10 \%$ is adopted from Efroymson et al. (2016). This is higher than the discount rate $(6.5 \%)$ assumed in analyses of terrestrial feedstocks. However, it is lower than the cost of capital that might be required for risk financing. Therefore, this rate constitutes a large source of uncertainty in the analysis. Moreover, in the techno-economic analyses for several complete algal biofuel supply chains in Beal et al. (2015), the minimum bio-crude price is highly sensitive to the discount rate, as well as the interest rate, loan term, and tax rates. Upon further study in the model, improvements in dewatering only reduce the cost of energy production from 0.5 to $1 \mathrm{US} \$ / \mathrm{GJ}$ for algal fuel. A $5 \%$ increase in interest rate from zero to $5 \%$ leads to increases of the total energy cost of 7\%, 11\%, 13\%, and 19\% for Algal slurry, Open Raceway Ponds (ORP) New Mexico (NM), PBR Arizona (AZ), and PBR-ORP Hawaii (HI), respectively, and from $5 \%$ to $10 \%$, the increase in total energy cost was $9 \%$, $12 \%, 15 \%$, and $19 \%$, respectively. The rate of increase in total energy cost correlates with capital equipment costs.

Figure 5 shows the differences in net and gross energy yield between the biomass fuel production schemes, showing that PBR systems do not lead to positive energy gains.

Upon examination of the energy output, we see the algal systems are not big net energy gainers, except in the case of ORPs in New Mexico. Yet, the EROI is greater for all terrestrial crops than for algal crops shown in Figure 6.

Algal production systems may produce more biomass than terrestrial crops but the required input energy and component costs are too large to allow the production of low cost fuels or provide a high return on investment. Similarly, the carbon balance of the biofuel production systems presented in Figure 7 shows that the lowest GHG emissions are associated with corn grain ethanol. This is driven by high corn yields and ease of starch to ethanol conversion relative to the difficulties of lignocellulosic fuel processing. Although biofuels

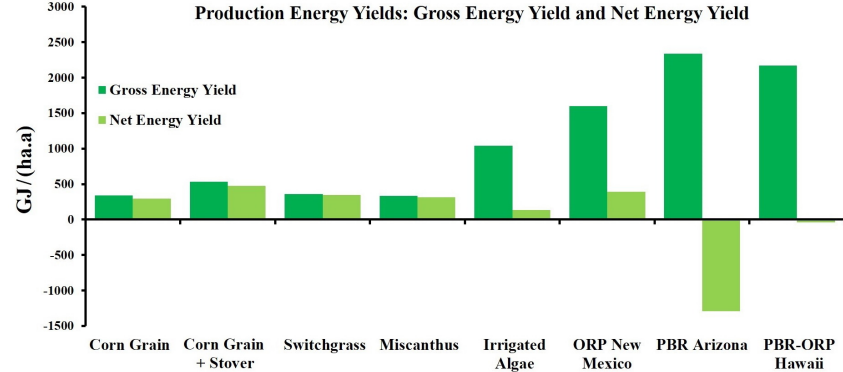

Fig. 5. Net energy as compared to Gross energy on an areal basis.

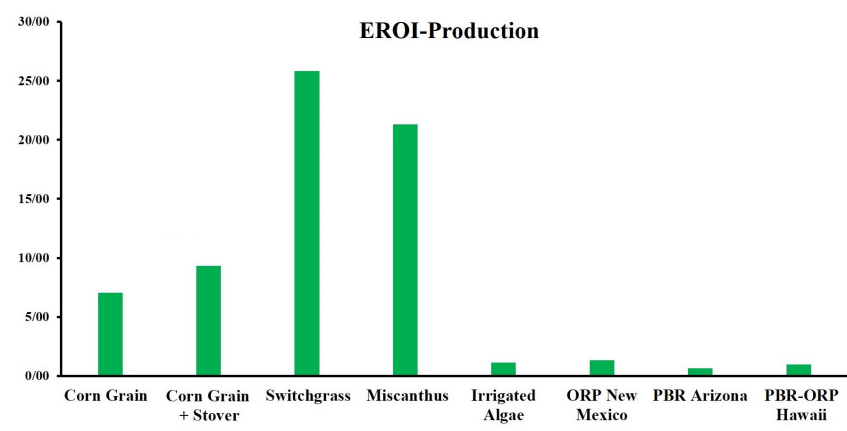

Fig. 6. Energy return on investment with co-product credits.

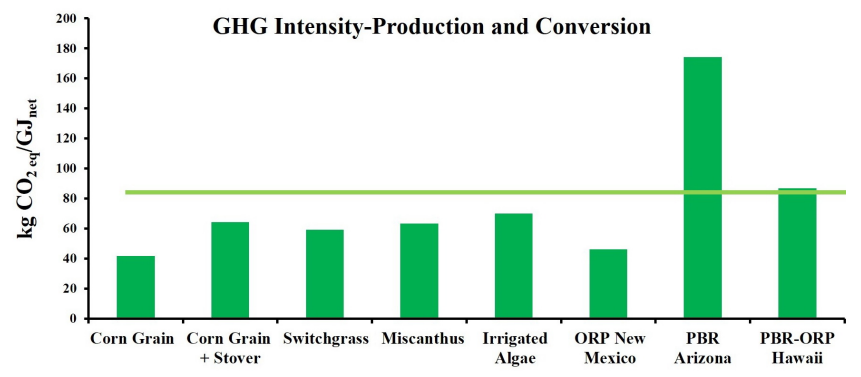

Fig. 7. Carbon dioxide equivalent emissions per net energy production unit.

are often promoted as a way to address climate change, none of the biofuel scenarios result in a negative net GHG balance.

The high-energy input cost for algal system is obvious in EROI comparisons with terrestrial crops. The largest algal scenario EROI is less than the lowest terrestrial crop EROI. Given currently available conversion technologies, algal biofuel scenarios are unattractive both economically and energetically. Secondary benefits from algae cultivation, however, such as nutraceutical production, are not considered here and are likely critical to the growth of the nascent algal biomass industry.

\section{Conclusions and policy implications}

The static, algebraic, spreadsheet-implemented modeling approach described here allowed us to estimate the costs, energy inputs and outputs, and global warming potential of biomass feedstocks. While simplistic in conception and execution, this approach allowed insight into the cost structure and attendant energetic implications of current, near future, and distant future biomass to fuel systems. What is striking in these results is the capital intensity of algal fuels. Capital does not assemble itself without energy investments, and by using an Economic Input-Output Life Cycle 
Assessment (EIO-LCA) approach to estimate the energy requirements for algal biofuels, the EROI appears extremely small. In contrast, the EROI for perennial lignocellulosic feedstocks is quite high (ca. 25), but like algal fuels, their deployment at this writing is minimal. The challenges for algal and terrestrialperennial biomass feedstocks are different: our work suggests that algal approaches need to find order-of-magnitude decreases in capital outlay without sacrificing yield, the work of others suggests perennial biomass feedstocks need to overcome challenges of low energy density feedstocks, solids processing and transportation and storage logistics. A wild but potentially fruitful research shift would be to abandon slow progress in reducing algal production costs and lignocellulosic fuel conversion costs and explore increasing the oil production in Maize kernels. This effort is not so far-fetched given all of the successful genetic manipulation and breeding with Maize. Doing so would increase the energy density of the feedstock, lower fuel conversion costs (biodiesel instead of ethanol), and not have the capital and stand investment issues associated with other feedstocks.

\section{Acknowledgements}

The authors would like to thank honor students Debanjan Gosh, Benjamin Rome, and Nikhal Shah for literature research as well as former students Jenny Cadwallader, David Escudero, Carol Faulhaber, Andrew Johnson, Vineeth Kisara, Matthew Kronlage, Rachel McDaniel, Laura Slimak, Stephanie Swanson, Randy Swestka, \& Phillip Tedja for assistance with preliminary model inputs.

The work was supported by:

- USDA Higher Education Challenge Grant Award: \#20006-38411-17084

- Iowa State University Biobased Industry Center Project: Costs and Lifecycle Carbon Footprints of Existing and Proposed Biofuel Feedstocks: Algae, Miscanthus, Switchgrass, and Corn

\section{References}

[1] Beal, C.M., Gerber, L.N., Sills, D.L., Huntley, M.E., Machesky, S.C., Walsh, M.J., Tester, J.W., Archibald, I., Granados, J., Greene, C.H., 2015. Algal biofuel production for fuels and feed in a 100-ha facility: a comprehensive techno-economic analysis and life cycle assessment. Algal. Res. 10, 266-279.

[2] Biofuels, 2015. In OECD-FAO Agricultural Outlook 2015. OECD Ilibrary, Paris

[3] Carlton, J.S., Perry-Hill, R., Huber, M., Prokopy, L.S., 2015. The climate change consensus extends beyond climate scientists. Environ. Res. Lett. 10(9), 094025

[4] Carnegie Mellon University Green Design Institute, 2008. Economic input-output life cycle assessment (EIO-LCA). US 1997 Ind. Benchmark model.

[5] Chisti, Y., 2007. Biodiesel from Microalgae. Biotechnol. Adv. 25(3), 294-306.

[6] Clark, S., Klonsky, K., Livingston, P., Temple, S., 1999. Crop-yield and economic comparisons of organic, low-input, and conventional farming systems in California's Sacramento Valley. Am. J. Altern. Agric. 14(3), 109-121

[7] Cook, J., Oreskes, N., Doran, P.T., William, R.L., Anderegg, W.R., Verheggen, B., Maibach, E.W., Carlton, J.S., Lewandowsky, S., Skuce, A.G., Green, S.A., Nuccitelli, D., 2016. Consensus on consensus: a synthesis of consensus estimates on human-caused global warming. Environ. Res. Lett. 11(4), 048002.

[8] Detwiler, P.K., 2013. As solar panel efficiencies keep improving, it's time to adopt some new metrics. Forbes.com.

[9] Efroymson, R., Coleman, A., Wigmosta, M., Schoenung, S., Sokhansanj, S., Langholtz, M., Davis, R., Microalgae. In. U.S. Department of Energy, 2016. 2016 Billion-Ton Report: Advancing Domestic Resources for a Thriving Bioeconomy, Volume 1: Economic Availability of Feedstocks, M.H., Langholtz, B.J., Stokes, L.M., Eaton (Leads), ORNL/TM-2016/160. Oak Ridge National Laboratory, Oak Ridge, TN. 448

[10] Energy Information Administration, 2018. U.S. ethanol exports rise 26\% in 2016 to second-highest level on record. Today in Energy.

[11] Ethanol Producer magazine, 2018. U.S. Ethanol Plants.
[12] Gomiero, T., Paoletti, M.G., Pimentel, D., 2015. Biofuels: efficiency, ethics, and limits to human appropriation of ecosystem services. J. Agric. Environ. Ethics. 23(5), 403-434.

[13] Gornall, J., Betts, R., Burke, E., Clark, R., Camp, J., Willett, K., Wiltshire, A., 2010. Implications of climate change for agricultural productivity in the early twenty-first century. Philos. Trans. R. Soc. London, Ser. B. 365(1554), 2973-2989.

[14] Hess, J.R., Wright, C.T., Kenney, K.L., 2007. Cellulosic biomass feedstocks and logistics for ethanol production. Biofuels, Bioprod. Biorefin. 1(3), 181-190

[15] Hill, J., Nelson, E., Tilman, D., Polasky, S., Tiffany, D., 2006. Environmental, economic, and energetic costs and benefits of biodiesel and ethanol biofuels. PNAS. 103(30), 11206-11210.

[16] Hill, J., Tajibaeva, L., Polasky, S., 2016. Climate consequences of low-carbon fuels: The United States renewable fuel standard. Energy Policy. 97, 351-353.

[17] Huisingh, D., Zhang, Z., Moore, J.C., Qiao, Q., Li, Q., 2015. Recent advances in carbon emissions reduction: policies, technologies, monitoring, assessment and modeling. J. Cleaner Prod. 103, 1-12.

[18] Jaggard, K.W., Qi, A., Ober, E.S., 2010. Possible changes to arable crop yields by 2050. Philos. Trans. R. Soc. London, Ser. B. $365(1554), 2835-2851$

[19] Keyzer, M.A., Merbis, M.D., Voortman, R.L., 2008. The biofuel controversy. De Economist. 156(4), 507-527.

[20] Langholtz, M.H., Stokes, B.J., Eaton, L.M., Brandt, C.C., Davis, M.R., Theiss, T.J., Turhollow Jr, A.F., Webb, E., Coleman, A., Wigmosta, M., Efroymson, R.A., 2016. 2016 Billion-ton report: advancing domestic resources for a thriving bioeconomy, volume 1 economic availability of feedstocks. Oak Ridge National Lab.(ORNL), Oak Ridge, TN (United States).

[21] Leung, D.Y., Caramanna, G., Maroto-Valer, M.M., 2014. An overview of current status of carbon dioxide capture and storage technologies. Renew. Sust. Energy Rev. 39, 426-443.

[22] Lobell, D.B., Cassman, K.G., Field, C.B., 2009. Crop yield gaps: their importance, magnitudes, and causes. Annu. Rev. Environ. Resour.

$34,179-204$

[23] Mearian, L., 2015. SolarCity claims it has created the world's most powerful solar panel. Computer World.

[24] Nielsen, R.L., 2017. Historical Corn Grain Yields for the U.S Corny News Network

[25] Otto, C.R., Roth, C.L., Carlson, B.L., Smart, M.D., 2016. Land-use change reduces habitat suitability for supporting managed honey bee colonies in the Northern Great Plains. PNAS. 113(37), 1043010435.

[26] Pacala, S., Socolow, R., 2004. Stabilization wedges: solving the climate problem for the next 50 years with current technologies. Science. 305(5686), 968-972.

[27] Pienkos, P.T., Darzins, A.L., 2009. The promise and challenges of microalgal-derived biofuels. Biofuels, Bioprod. Biorefin. 3(4), 431440

[28] Richard, T.L., 2010. Challenges in scaling up biofuels infrastructure. Science. 329(5993), 793-796.

[29] Schuur, E.A., Bockheim, J., Canadell, J.G., Euskirchen, E., Field, C.B., Goryachkin, S.V., Hagemann, S., Kuhry, P., Lafleur, P.M., Lee, H., Mazhitova, G., Nelson, F.E., Rinke, A., Romanovsky, V.E. Shiklomanov, N., Tarnocai, C., Venevsky, S., Vogel, J.G., Zimov, S.A., 2008. Vulnerability of permafrost carbon to climate change: implications for the global carbon cycle. BioSci. 58(8), 701-714.

[30] Singh, J., Suhag, M., Dhaka, A., 2015. Augmented digestion of lignocellulose by steam explosion, acid and alkaline pretreatment methods: a review. Carbohydr. Polym. 117, 624-631.

[31] Taylor, D.K. D.R., Rank, D.R., Keiser, B.N., Smith, R.S., Criddle, L.D., 1998. Modeling temperature effects on growth-respiration relations of maize. Plant, Cell Environ. 21(11), 1143-1151.

[32] Tomei, J., Helliwell, R., 2016. Food versus fuel? going beyond biofuels. Land Use Policy. 56, 320-326.

[33] Wang, M.Q., 1999. GREET 1.5-transportation fuel-cycle modelVol. 1: methodology, development, use, and result. ANL/ESD-39, Center for Transportation Research, Argonne National Lab. Argonne, IL (US). 


\section{Supplementary: FEBEF Methodology}

Ten worksheets comprise FEBEF, as follow: (a) Background Assumptions and Calculations (1. BACC, 2. BACC-Crop, 3. BACC-EconAsmp, 4. BACCEIOLCA, 5. BACC-Fertilizer, and 6. BACC-Solar, containing conversion factors, constants, elemental compositions for the different feedstocks, and climatic data inputs for the model). (b) Cost $v s$. Yield, containing literaturebased (Vadas et al., 2008; Edwards, 2009; Smeets et al., 2009) factors to enable production costs to scale on predicted yields assuming that each line-item in the cost model is either linearly-dependent on yield, or completely independent of yield. (c) Algae Cost Model, modeling algal production costs in ORPS, based primarily on Vadas et al. (2008), scaled to 100 ha. This worksheet also includes free water surface evaporation estimates to enable water consumption calculations. (d) Primary Assumptions, containing location and cropphysiological factors, crop-cost components, EIO-LCA GHG and Energy computations. (e) Primary Results, containing intermediate and final computations for model outputs. The fourth and fifth worksheets constitute the core of the model. In both worksheets, feedstocks are organized in columns so that cross comparisons between feedstock can be made readily.

The approach of FEBEF is as follows: Compute an energy-limited carboncapture by using growing-season solar energy inputs coupled with knowledge of the maximum photosynthetic rates of each feedstock. Similarly, compute a water-limited carbon-capture by using growing-season rainfall coupled with knowledge of the maximum WUE of each feedstock. De-rate both these carbon-capture estimates to account for multiple losses such as respiration and non-harvestable fraction, to estimate a light-limited and water-limited yield. Pick the lower of the two to estimate the biomass yield. The biomass yield is then used to calculate theoretical energy and biofuel yields. Break the cost of production and fuel conversion into fewer than a dozen line-items that are common across feedstocks, and use literature estimates to populate those cost estimates. Scale some of the line-items by yield (details below). Use an EIOLCA approach to compute the embedded energy and GHG emissions from each cost line-item; sum both of these to find total embedded energy and GHG for each feedstock. With maximum yield, cost, energy input, and GHG emissions for each feedstock, key model outputs can be computed. These outputs are presented in Table S1.

\section{S1. Background Assumptions and Calculations Worksheet}

The BACC worksheets contain the following: BACC: (a) Text-color conventions used in the workbook. (b) Common conversion factors in named cells (e.g., cell B12 is named $\mathrm{kg}$ per $M g$ and has a value of 1000). These conversions can be referred to by name elsewhere to reduce the incidence of hard-coding errors in the spreadsheet. (c) Molecular weights and densities of relevant materials. (d) Energy Contents and Thermodynamic Conversions. BACC-Crop: (a) Computations to convert literature data into ratios of root-exudate carbon to root stored carbon for Switchgrass and Miscanthus. (b) A listing of best-reported yields for each biomass type. Ideally these would be from identical environments in plots greater than 10 ha as the modeled case (central Iowa in this work), but this was only possible for corn; values for Switchgrass, Miscanthus, and algae were from more distant sites. (c) Theoretical limits on plant physiological parameters to allow an upper bound on the performance of the biomass. BACCEconAsmp: (a) Economic assumptions including interest rates, utility prices, and inflation factors. (b) Raw data and linear regression of land rental costs $v s$. productivity data. (d) (f) (g) (i) BACC_EIO-LCA energy multiplier factors for perennial grass seeding. BACC-Fertilizer: (a) Fertilizer costs and pre-computations. (b) Fertilizer application rate crosscheck. BACC-Solar Solar and precipitation values. This includes raw meteorological data as well as data modified by the planting and harvesting dates listed in the Primary Assumptions worksheet.

\section{S2. Cost vs. Yield Worksheet}

The Cost vs. Yield worksheet (CvsY) scales line item production costs based upon predicted yields by assuming that some line items are yieldindependent (i.e., scale factor $\mathrm{n}=0$ ), while others are linearly scaled with yield $(\mathrm{n}=1)$. This binary segregation of costs is an oversimplification, but one which provides overall cost $v s$. scale responses is consistent with those reported for corn (data not shown). The yield-appropriate costs computed in the $\mathrm{C} v s \mathrm{Y}$ worksheet are used by the Primary Assumptions worksheet in the core cost model.

\section{S3. Algae Cost Model Worksheet}

The Algae Cost Model worksheet (ACM) contains the amortized capital, labor, irrigation, and direct energy cost calculations and free water evaporation calculation for three different algal production technologies in four different locations. The three different types of algal plants and the locations are ORP in Ames, IA, ORP in Tucumcari, NM, PBR in Phoenix, NM, and a coupled PBR-ORP system in Honolulu, HI. Each operation was assumed to have 100 ha production area. The amortized capital cost, labor,

Table S1.

Conversion computations and key model outputs added to FEBEF.

\begin{tabular}{|c|c|c|}
\hline Output & Units & Abbreviation \\
\hline Maximum Energy Yield Gross & $\mathrm{GJ} /(\mathrm{ha} \cdot \mathrm{a})$ & $\mathrm{MEY}_{\mathrm{G}}$ \\
\hline Maximum Harvestable Yield & $\mathrm{Mg} /(\mathrm{ha} \cdot \mathrm{a})$ & MHY \\
\hline Energy Return on Investment & Dimensionless & EROI \\
\hline Biomass Production Cost & $\begin{array}{l}\text { US } \$ / \text { ton - in US customary units for easy comparison to existing } \\
\text { feedstock prices }\end{array}$ & $\mathrm{BPC}$ \\
\hline GHG-Areal & $\mathrm{kg} \mathrm{CO}_{2 \text { eq }} /(\mathrm{ha} \cdot \mathrm{a})$ & - \\
\hline GHG Intensity & $\mathrm{kg} \mathrm{CO}_{2 \mathrm{eq}} / \mathrm{GJ}$ & - \\
\hline Transportation Fuel Energy Out & $\mathrm{GJ}_{\text {out }} / \mathrm{Mg}$ Biomass & TFEO \\
\hline Maximum Fuel Energy Yield -Net Converted & $\mathrm{GJ} /(\mathrm{ha} \cdot \mathrm{a})$ & $\operatorname{MFEY}_{\mathrm{NC}}$ \\
\hline Maximum Fuel Energy Yield -Net Converted with Co-Product Credit & $\mathrm{GJ} /(\mathrm{ha} \cdot \mathrm{a})$ & MFEY $_{\mathrm{NC}-\mathrm{CCP}}$ \\
\hline Carbon Intensity of Fuel Energy Source & $\mathrm{kg} \mathrm{CO}_{2 \mathrm{eq}} / \mathrm{GJ}$ & CIFES \\
\hline
\end{tabular}


and direct energy estimates for the production scenarios were based on literature reports, updated for inflation, and supplemented with engineering estimates when data was lacking. The irrigation costs were calculated from local pan evaporation data, growing season rainfall, and water rates.

\section{S3.1 ORP in Ames, IA}

The ORP amortized capital costs were based on the $400 \mathrm{ha}, 30 \mathrm{~g} / \mathrm{m}^{2} / \mathrm{d}$ production scenario using pure carbon dioxide outlined by Benemann and Oswald (1994). Capital costs for conversion equipment of algae oil to biodiesel, listed in the original publication, are excluded as a different source/method is used for fuel conversion capital cost estimates.

Line item capital costs were adjusted for inflation from 1994 dollars to 2008 dollars as shown in Equation 1.

Inflation adjusted cost for year $y=$ Known cost in year $x \times$ $\left(\frac{\text { Inflaction index factor for year } y}{\text { Inflation index factorfor year } x}\right)$

The total cost per line item for the 400 ha system was calculated. Using scale factors, assigned using engineering judgment to each line item, a total cost per line item for a 100 ha system is calculated as shown in Equation 2.

Predicted Cost of spec $^{\prime} d$ eqp $=$ Known Cost of baseline eqp $\times$ (Size of spec'd eqp $)^{\text {sizing exponent }}$

$\left(\frac{\text { size of baseline eqp }}{\text { size }}\right.$

(Eq. 2)

The sum of the line items gives a total capital investment. The yearly capital charges are calculated using the PMT function in Excel; the annual rate of return assumed in $10 \%$, over a 20 -year period, and total capital investment was the principal. The yearly capital charges (US \$/a) is divided by 100 ha and converted to the reported estimate of amortized capital in US \$/(acre.a).

The labor costs were based on Benemann and Oswald (1994) and were adjusted for inflation and seasonal labor needs. The baseline labor rate in US \$/(ha.a) was adjusted for inflation as shown in Equation 1. The labor was prorated for the variation in the seasonal labor needs, as shown in Equation 3:

Labor rate $=$ Inflation Corrected Labor Rate $\times$

(Fraction of Year Growing Algae + Fraction of Year Idle $\times$

Personnel Requirements in Off Season)

This prorated value was then scaled by system size, and adjusted for inflation.

The direct energy estimate was based on Benemann and Oswald (1994). The power requirements $(\mathrm{kWh} /(\mathrm{ha} \cdot \mathrm{a}))$ for mixing, centrifugation, water pumping, and other (nutrient pumping and building needs) were summed to find the total power requirement. The total power requirement $(\mathrm{kWh} /(\mathrm{ha} \cdot \mathrm{a}))$ was then multiplied by the local electricity rate (US $\$ / \mathrm{kWh}$ ) (Energy Information Administration, 2010) to give a direct energy cost in (US $\$ /($ ha $\cdot a)$ ), which was converted to US \$/(acre.a) as reported in the Primary Assumptions worksheet.

The irrigation costs for all of the algal production scenarios in the four different locations were estimated using the same method. We assumed that the evaporation of the free standing water at the different production plants was similar to lakes (Linacre, 2018), and that all of the evaporation occurred during the growing season. Local pan evaporation data (in/a) (Western Regional Climate Center, 1986) was manipulated by pan to lake evaporation factor, as shown in Equation 4.

Lake evaporation $\left(\frac{i n}{a}\right)=$ Pan evaporation $\left(\frac{i n}{a}\right) \times$

Ratio of Lake to Pan Evaporation

Then, daily evaporation rate was calculated as shown in Equation 5.

Daily Evaporation $\left(\frac{\mathrm{cm}}{\mathrm{d}}\right)=$ Lake evaporation $\times \frac{(\mathrm{cm} / \mathrm{in})}{\text { Season length }(\mathrm{d})}$

The daily evaporation rate was converted to $\mathrm{m}^{3} / \mathrm{d}$. The mass of water evaporated is calculated as shown in Equation 6.

$$
\begin{aligned}
\text { Mass water evaporated } & \left(\frac{\mathrm{kg}}{\mathrm{d}}\right) \\
= & \text { Daily evaporation }\left(\frac{\mathrm{m}^{3}}{\mathrm{~d}}\right) \times \text { Density of water }\left(\frac{\mathrm{kg}}{\mathrm{m}^{3}}\right)
\end{aligned}
$$

As a cross-check, an effective "WUE" was calculated for the algal scenarios as shown in Equation 7:

$W U E=\frac{\left(\frac{\text { Maximum Harvestable Yield }\left(\frac{\mathrm{Mg}}{\mathrm{ha}}\right)}{\text { Season Length-days }} \times \frac{1000 \mathrm{~kg}}{\mathrm{Mg}} \times 100 \mathrm{ha}\right)}{\text { Mass water evaporated } \mathrm{kg} / \mathrm{d}}$

Water use was corrected for local, annual precipitation as shown in Equation 8.

$$
\begin{aligned}
& \text { WWater Use】_(precipitation corrected })(\mathrm{m} / \text { season }) \\
& \quad=[((\text { Evap. Rate }(\mathrm{cm} / \mathrm{d}) \times \text { Grow.Seas. Leng. }(\mathrm{d})) \\
& -(\text { Precip. }(\mathrm{cm} / \mathrm{a}) \\
& \left.\times \text { Frac. Water Avail.During Grow. Seas. })) /\left(\frac{\mathrm{cm}}{\mathrm{in}}\right)\right]
\end{aligned}
$$

The volume of water evaporated over the whole free water area corrected for precipitation was calculated as shown in Equation 9.

$$
\begin{aligned}
\text { Water Use } & \text { precip.corr. } \\
& \left(\frac{f t^{3}}{a}\right) \\
& =\text { Water Use } \text { precip.corr. }\left(\frac{m}{\text { season }}\right) \times 100 h a \\
& \times m^{2} / h a \times f t / m^{3}
\end{aligned}
$$

For the PBR in Phoenix, AZ, the calculation was adjusted to correct for the area of water baths, which was a fraction of the 100 ha.

Annual irrigation costs were calculated by multiplying the local industry water rates (US \$/cubic feet) (Tucumcari, 2004; City of Phoenix Water Rates, 2010; City and County of Honolulu, 2015) by the Seasonal Water Use (cubic feet/season). The irrigation costs on an area basis are calculated as shown in Equation 10.

Irrigation costs $(U S \$ / h a / a)=\frac{\text { Yearly Irrigation } \operatorname{Cost}\left(\frac{U S \$}{a}\right)}{100 h a}$

The irrigation costs (US \$/(ha.a)) are converted to a US \$/(acre.a) basis.

\section{S3.2 Algae Harvesting}

The harvesting of algae from the production reactors (ORPs or PBRs) included the capital costs for a primary settling followed by centrifugation. We assumed the centrifugation produced $15 \%$ solids from the ORP systems and $20 \%$ solids from the PBR systems. For the ORPs, we calculated the additional direct energy required to reach $20 \%$ solids, as shown in Equation 11.

Direct Energy $_{\text {algae slurry }}=\mathrm{MHY} \times \operatorname{Hvap} \times \mathrm{MR} \% \times(\mathrm{MC} \% /(1-\mathrm{MC} \%)) \quad($ Eq. 11$)$

Where, Hvap is the heat of vaporization for water, MR\% is the moisture (\%) needed to remove to reach $10 \%$ solids, and $\mathrm{MC} \%$ is the moisture content of the slurry exiting the centrifuge.

\section{S3.3 ORP in Tucumcari, NM}

The approach for computing amortized capital costs and labor costs was identical to that used for Ames, IA. The direct energy and irrigation costs used the same method but with electricity and water rates specific to Tucumcari, NM. 


\section{S3.4 PBR in Phoenix, NM}

The PBR amortized capital costs were based on Grima et al. (2003) report on commercial production of microalgae in PBRs. The basis of that study was a facility with a projected biomass productivity of $1.25 \mathrm{~kg} / \mathrm{m}^{3} / \mathrm{d}$ (approximately $10.7 \mathrm{~g} / \mathrm{m}^{2} / \mathrm{d}$ ) in continuous culture. We included only the unit operations and the associated costs needed for the cultivation of the algae and up through harvesting the algae.

The original line item capital costs included in the amortized capital estimate in 2001 dollars were adjusted for inflation as shown in Equation 1 to 2008 dollars. The cost estimate was then scaled from the area of foot print (approximately $1 \mathrm{ha}$ ) of the PBR calculated from measurements given in Grima et al. (2003) to a 100 ha area using Equation 2.

The centrifugation costs provided by Grima et al. (2003) were replaced with a yield scaled centrifugation cost from Vadas et al. (2008) as shown in Equation 12. This allowed for consistency with the same unit operation across technologies.

$$
\begin{aligned}
& \text { Centrifugation costs } \text { tech }_{\text {(US US \$) }} \\
& \begin{array}{l}
=\left(\frac{\text { Maximum Harvestable Yield }_{\text {tech }}}{\text { Maximum Harvestable Yield }_{O P R}}\right) \\
\times \text { Centrifugation Costs }_{O P R}
\end{array}
\end{aligned}
$$

The total capital cost was the summation of the scaled costs. The yearly capital charge was computed using an annual rate of return at $10 \%$ over a 20 year period. The yearly capital charge (US \$/a) was divided by 100 ha and converted to the reported estimate of amortized capital in US \$/(acre.a).

The labor costs were based on Grima et al. (2003), adjusted for inflation and scale. These labor costs were prorated based on the growing season length (fewer workers off season).

The direct energy estimate was also based on the Grima et al. (2003), using local electrical rates (Energy Information Administration, 2010) in Phoenix, $\mathrm{AZm}$ and converted to US $\$ /($ acre.a) for the direct energy costs

\section{S3.5 Coupled PBR-ORP system in Honolulu, HI}

The Coupled PBR-ORP amortized capital costs based primarily on Huntley and Redalje (2007) which reported the general specifications of the Aquasearch (now HP petroleum) coupled production systems for photosynthetic microbes. Biomass production was estimated at $10.2 \mathrm{~g} / \mathrm{m}^{2} / \mathrm{d}$ for the PBR and $15.1 \mathrm{~g} / \mathrm{m}^{2} / \mathrm{d}$ for the ORPs. The authors of Huntley and Redalje (2007) relied on the Benemann and Oswald (1994) techno-economic analysis (adjusted for inflation) for capital costs for the ORPs, and on Hallenbeck and Benemann (2002) for PBR cost estimates. We included only the unit operations and the associated costs needed for the cultivation of the algae and up through harvesting the algae.

Capital costs were adjusted for inflation and scaled. Centrifugation costs were calculated as outlined above using Equation 11 . The yearly capital charge was computed using an annual rate of return at $10 \%$ over a 20 -year period. The yearly capital charge (US \$/a) was divided by 100 ha and converted to the reported estimate of amortized capital in US $\$ /$ (acre.a).

The labor costs were calculated based on both the previous PBR and ORP labor estimates. The percentage areas of the PBR and ORP unit operations of the total operational area were calculated. The labor costs for the coupled system were estimated by distributing the percentage area with the labor costs, as shown in Equation 13.

Labor cost PBR-ORP $_{P B R}$ area $\% \times$ Labor Cost $_{P B R}+$ ORP area $\% \times$ Labor Cost $_{\text {ORP }}$

These labor costs were prorated based on the growing season length (fewer workers off season).

The direct energy costs were calculated from the previous PBR and ORP power estimates. The power needs for the coupled system were estimated by distributing the percentage area with the direct energy estimates, as shown in Equation 14.
Power Requirement ${ }_{P B R-O R P}\left(\frac{k W h}{h a \cdot a}\right)=P B R$ area $\% \times$

Power Requirement $_{P B R}+$ ORP area $\% \times$ Power Requirement $_{O R P}$

This estimated power requirement was then multiplied by the electricity rates in HI (Energy Information Administration, 2010) to calculate the direct energy cost in US $\$ /(h a \cdot a)$ and then converted to US $\$ /($ acre.a).

\section{S4. Primary Assumptions Worksheet}

The Primary Assumptions worksheet (PA tab) compiled literature-based measurements and assumptions about climate, plant growth, production costs, energy requirements, GHG emissions, water use, and eutrophication potential. In some cases, data came directly from literature sources, while in others, it was based on computations in the supporting worksheets that have been previously described. In all cases, the data for each feedstock was organized in a single column. Details of the contents of the Primary Assumptions worksheet follow:

\section{S4.1 Location-Specific Climatic Assumptions}

Annual average solar irradiation $\left(\mathrm{W} / \mathrm{m}^{2}\right)$ (Marion and Wilcox, 1995), fraction of solar radiation in as photosynthetically available radiation (PAR) (Bolton and Hall, 1991), annual total rainfall (http://www.weatherbase.com/weather/state.php3?c=US\&refer), planting date, and harvesting date (Neild and Newman, 1990; Wolf and Fiske, 1995 Chisti, 2007) are the four fundamental assumptions entered into the climate section of the model. These fundamental assumptions are used to compute growing season length, fraction of solar available during growing season, and fraction of water available during growing season. To find the latter two items, intermediate calculations are conducted in the Background Assumptions and Calculations worksheet.

\section{S4.2 Crop Physiological Assumptions}

Crop performance data and cost estimates are based on literature values without extrapolations based on future technological advances.

\section{Literature Reported RUE values}

RUE is a measure of biomass accumulation given PAR. Instantaneous RUEs ( $\mathrm{g}$ of biomass/MJ of PAR) were estimated for $\mathrm{C} 4$ plants from Nobel (1991) and for algae from Melis (1998) by converting gas evolved $\left(\mathrm{CO}_{2}\right.$ or $\mathrm{O}_{2}$ ) and photon flux density converted to an RUE.

\section{RUE actual to RUE Theoretical Maximum Ratio (RUER)}

The maximum theoretical RUE is assumed to be $30 \%$ on PAR basis (Bolton and Hall, 1991). The ratio of the crops' actual RUE to the RUE theoretical maximum is calculated by FEBEF, as shown below in Equation 15, where RSR is the Root: Shoot Ratio at harvest:

$R U E R=\left(\frac{R U E_{\text {actual }}\left(\frac{\text { gbiomass }}{M J}\right) \times \text { Biomass Energy Content }\left(\frac{M J}{g}\right)}{R U E_{\text {Max }}\left(\frac{g \text { biomass }}{M J}\right)}\right) \times(1+R S R)$

\section{Literature Reported WUE Values}

The instantaneous WUE values for the terrestrial crops, defined as the ratio of biomass accumulated to crop water transpired, was experimentally determined in Rochette et al. (1996), and these values were used in the model. The term WUE is normally not used when referring to aquatic plants. However, if one pictures the entire culture system as a giant "leaf," an effective WUE can be computed. The WUE of the algal crop was computed as the growing season evaporation from pond divided by the algal biomass produced. The transpiration calculations were previously described in Equation 7. 


\section{WUE actual to WUE Theoretical Maximum Ratio (WUER)}

The theoretical maximum WUE was estimated based on an assumed leaf temperature, ambient relative humidity, maximum net photosynthetic rate, and water vapor flux for a typical Iowa crop. The calculations were shown in the Background Assumptions Worksheet. The value estimated and used in the model was $0.02 \mathrm{~kg}$ biomass $/ \mathrm{kg}$ water.

\section{Respiration Loss of Fixed C (RLC) - Growing Seasonal Average (GSA)}

Stored chemical energy is lost via respiration which supports physiological needs including transportation and translocation of nutrients, protein and lipid synthesis, and cellulose synthesis. While the respiration losses are dependent on the needs the plant, we estimated growing seasonal average (Taylor et al., 1998).

\section{Root: Shoot Ratio@ harvest (RSR)}

This experimentally determined value is the ratio of dry belowground structural root biomass to dry aboveground biomass. Literature-reported values for the different terrestrial crops were used (Kiniry et al., 1999; Kahle et al., 2001; Bonifas et al., 2005).

\section{C to soil organisms / C in root (GSA) CSORR}

For terrestrial crops, a fraction of the carbon captured is transferred to the soil in the form of root turnover, root cap mucigel, and organic exudates (Amos and Walters, 2006). Literature-reported values for net rhizodeposited carbon for the different terrestrial crops were converted to a root basis ratio (Frank et al., 2004; Wanga et al., 2005; Amos and Walters, 2006). Those conversion calculations were done in the Background Assumptions worksheet.

\section{Fraction of Stover Collected}

In light of equipment collection limitations and sustainable collection guidelines, the fraction of corn stover collected was assumed to be $60 \%$ (Glassner et al., 1998).

\section{Harvestable Fraction of Above Ground Biomass $\left(h f_{A G B}\right)$}

This factor accounted for mechanical limitations of the production harvest systems. Literature-reported values for the different terrestrial crops and algae were used (El Bassam and Huisman, 2001; Vogel, 2002; Huntley and Redalje, 2007; Johnson, 2007).

\section{Harvestable Fraction of Total Biomass $\left(h f_{T B}\right)$}

This factor accounted for the belowground biomass and was calculated in FEBEF by Equation 16, as shown below:

$h f_{T B}=\frac{\text { Harvest Index }}{1+R S R}$

\section{Harvestable Fraction of Total Fixed Carbohydrate $\left(h f_{T F C}\right)$}

This term represented the harvestable portion of carbon captured by the plant over the season. FEBEF calculated this factor by Equation 17:

$$
h f_{T F C}=\frac{h f_{A G B}}{(1+R S R+R S R \times(C S O R R)) \times(1-R L C)}
$$

\section{Biomass Energy Content (BEC)}

The higher heating values of the crops were experimentally determined and reported in (Beale and Long, 1995; McLaughlin, 1996; Hase et al., 2000; Brown Robert, 2003; Pordesimo et al., 2005) and were utilized in the model in units of $\mathrm{MJ} / \mathrm{kg}$.

\section{Biomass Moisture Content @ Harvest}

This factor was a literature based estimate for the amount of moisture remaining in the biomass following harvesting.

\section{Additional Moisture Removal Needed}

This is an estimate of the amount of moisture needed to be removed from the biomass to allow for storage and/or fuel processing.

\section{Direct Energy for Moisture Removal}

This calculation is described earlier in Equation 11 to estimate the additional direct energy required to reach $10 \%$ solids for the algae systems.

\section{Technological Improvement in Energy Reduction for Dewatering}

This value is an estimate that attempts to credit algal production technologies with harvesting developments that result in lower direct energy costs to meet desired moisture content levels.

\section{Direct Energy Cost for Moisture Removal}

This calculation estimates the direct energy cost needed to meet desired moisture content using natural gas to remove the moisture while also crediting for technological improvements to harvesting as shown in Equation 18:

$D E C=$

$\frac{\left(\text { Direct Energy algae slurry } \times 1000 \frac{\mathrm{kWh}}{\mathrm{MJ}} \times \frac{\mathrm{GJ}}{1000 \mathrm{MJ}} \times \text { Natural Gas Cost } \frac{\mathrm{US} S}{\mathrm{kWh}}\right) \times(1-\text { Technological Improvemnt for Dewatering })}{\left(2.471 \frac{\mathrm{accs}}{\mathrm{ha}}\right)}$

\section{S4.3 Crop-Cost Components}

Land rental cost was assumed to be proportional to biomass harvest. A linear regression model was developed from the reported cash rental rates and typical corn yields for high, medium, and low quality cropland (Edwards, 2009). Arguments have been made that feedstocks other than corn, including algae, for biofuels could be grown on marginal land and avoid competing for high value land, and therefore lower production costs. However, cash rental rates typically reflect average yields and we assume that this trend would apply to all bioenergy crops. The application of this model not only indirectly reflects nutrient removal from soil given yields for the terrestrial crops but also that higher output generates a surplus that is likely to be appropriated by the land owner in the charge of rent.

Amortized capital, labor, direct energy, biological capital, and lime and biocide costs for the terrestrial production scenarios were estimated by taking baseline values and either as is, or scaled to yield. Amortized capital costs were assumed independent of yield. While this is not true in the extremes - greater yields could conceivably require larger machinery - we argue it is a good first approximation. In contrast, labor costs, direct energy costs, and biological capital are assumed proportional to yield. Lime and biocides (pesticides, herbicides) are assumed to be independent of yield. Original production cost values were gleaned from Vadas et al. (2008) and Smeets et al. (2009). Chemical costs, while proportional to yield, were computed based on the $\mathrm{N}, \mathrm{P}$, and $\mathrm{K}$ content of the harvested biomass (Wallace, 1923; Zelibor et al., 1998; Lemus et al., 2002; Tokuşoglu and Üunal, 2003; Hoskinson et al., 2007; Johnson et al., 2007; Monti et al., 2008) and upon an assumption of the fraction of chemicals in the harvested biomass compared to the fraction applied. Irrigation costs for algal scenarios came from the algae cost model worksheet.

\section{S4.4 Single Pass Corn Grain and Stover Harvesting Assessment}

Based on Turhollow and Sokhansanj (2007) which assumes that 2/3 ( $10 \%$ more than for double pass) of the corn stover can be harvested in a single pass along with corn grain, with a reduced combine harvesting efficiency of $55 \%$ from $70 \%$, the following estimates were made 
concerning the crop cost component classes. Assuming a field harvest grind that achieves a bulk density of $74 \mathrm{dry} \mathrm{kg} / \mathrm{m}^{3}$ for the stover, the amortized capital costs are about $10 \%$ higher; as the combine costs increase by $30 \%$ but combine costs make up less than $40 \%$ of the amortized capital costs. Given the $15 \%$ decrease in harvest efficiency, the direct labor requirements increase by $15 \%$ and the direct energy increases by $30 \%$. These increases only result in a $3 \%$ increase overall from the system of two passes now modeled, so not that different. All crop cost components inputs used in the modeled are reported in 2009 US \$/(acre.a).

\section{S4.5 Economic Assumptions}

Utility, fuel, and chemical prices are highly volatile, and therefore introduce tremendous variability into the results of the analysis. These values are easily changed in the spreadsheet, but for the purposes of the analysis presented herein, the average value for 2007,2008 , and 2009 were used.

\section{S4.6 EIO-LCA Greenhouse Gas Computations}

The GHG emissions data were divided into two categories: direct emissions and indirect emissions. We used EIO-LCA model factors to estimate the supply chain, indirect $\mathrm{GHG}$ emissions (as $\mathrm{CO}_{2}, \mathrm{CH}_{4}$, and $\mathrm{N}_{2} \mathrm{O}$ ) from the EIO-LCA model developed by Carnegie Mellon University (Carnegie Mellon University Green Design Institute, 2008). The GHG emission rates (units of $\mathrm{CO}_{2 \text { eq }}$ ) were expressed on an areal $(\mathrm{Mg} \mathrm{CO} /(\mathrm{ha} \cdot \mathrm{a}))$ and net fuel $\left(\mathrm{Mg} \mathrm{CO}_{2} / \mathrm{GJ}_{\text {net }}\right.$ and ton $\mathrm{CO}_{2}$ /gallon-of-gasoline-equivalent) basis.

When considering direct emissions, the literature is split between the flux chamber and the soil organic carbon (SOC) methods, with flux chamber methods generally yielding higher $\mathrm{CO}_{2}$ emission estimates. An emission of $20.9 \mathrm{Mg} /(\mathrm{ha} \cdot \mathrm{a})$ was reported in Omonode et al. (2007) on the no-till operation system, an emission of $21.6 \mathrm{Mg} /(\mathrm{ha} \cdot \mathrm{a})$ for Moldboard Plow (MP) systems, and an emission of $22.7 \mathrm{Mg} /(\mathrm{ha} \cdot \mathrm{a})$ on short-term chisel (CP) systems. An emission of $16.1 \mathrm{Mg} /(\mathrm{ha} \cdot \mathrm{a})$ on various types of corn and soybean rotations was reported in Hernandez-Ramirez et al. (2009). In contrast, using a SOC method, Moiser et al. (2005) report an emission of $-0.6 \mathrm{Mg} /(\mathrm{ha} \cdot \mathrm{a})$ to $0.5 \mathrm{Mg} /(\mathrm{ha} \cdot \mathrm{a})$, depending on the farming operation management. This suggests that the long-term emission is negligible which is consistent with the guidelines by Intergovernmental Panel on Climate Change (IPCC). In Cherubini and Jungmeier (2010), the authors adopted a standard inventory time period of 20 years for the majority of bioenergy crops which means the field reaches a new equilibrium and carbon dioxide is no longer sequestered in soil organic matter. In this analysis, we adopted the SOC approach so that direct $\mathrm{CO}_{2}$ emissions were assumed to be negligible.

Methane constitutes less than $10 \%$ of the $\mathrm{N}_{2} \mathrm{O}$ emission when converting to $\mathrm{CO}_{2}$ emission equivalent measurement. Therefore, in this analysis, we assumed it is negligible as well.

Since $\mathrm{N}_{2} \mathrm{O}$ emission is most important component, we focused on $\mathrm{N}_{2} \mathrm{O}$ emission in our analysis. In Cherubini and Jungmeier (2010), the authors used synthetic fertilizer application rate to estimate $\mathrm{N}_{2} \mathrm{O}$ emissions. They reported that $1.325 \%$ of $\mathrm{N}$ in synthetic fertilizer is emitted as $\mathrm{N}$ in $\mathrm{N}_{2} \mathrm{O}$, implying 0.042 $\mathrm{g} \mathrm{N}_{2} \mathrm{O}$ emitted per $\mathrm{g} \mathrm{N}$ fertilizer applied. Using a multiplier of $296 \mathrm{~kg} \mathrm{CO}_{2 \mathrm{eq}} / \mathrm{kg}$ $\mathrm{N}_{2} \mathrm{O}$, we estimated the direct GHG emissions from each crop as $0.124 \mathrm{Mg} \mathrm{CO}_{2}$ ${ }_{\text {eq }} / \mathrm{kg} \mathrm{N}$ applied. When this was done for algae, the numbers were quite high, and were hard to compare with any existing literature because of a paucity of studies on direct GHG emission from algal systems. The researchers in Clarens et al. (2010) only included GHG emissions associated with the inputs for the production of algae, including $\mathrm{N}_{2} \mathrm{O}$ emissions. However, when direct $\mathrm{N}_{2} \mathrm{O}$ emissions from multiple green algae species grown in urea have been reported (Cherubini and Jungmeier, 2010), emission rates of up to $6.110^{-8} \mathrm{~mol}$ $\mathrm{N}_{2} \mathrm{O} / \mathrm{mg}_{\mathrm{dw}}$ were found, corresponding to roughly $60 \mathrm{Mg} \mathrm{CO}_{2 \mathrm{eq}} / \mathrm{MT}_{\text {dry }}$, which was the same order of magnitude estimated by our $0.124 \mathrm{Mg} \mathrm{CO}_{2 \text { eq }} / \mathrm{kg} \mathrm{N}$ applied method.

\section{S4.7 Indirect Emissions}

We found the EIO-LCA indirect greenhouse gas emissions multipliers for seven categories of economic activity in the production of biomass feedstocks. For the eighth category - biological capital - we computed an indirect GHG emission factor internally based on the direct emission values for each crop. The indirect greenhouse gas emissions were then calculated by multiplying the economic activity cost with the greenhouse gas emission multiplier. The economic activity and the EIO-LCA model categories are presented in Table S2 for all five production scenarios.

Table S2.

Pairings of categories for production activity and EIO-LCA factors.

\begin{tabular}{ll}
\hline Economic Activity & EIO-LCA Category \\
\hline Land rental & Real estate \\
Amortized capital & Amortized capital \\
Direct labor & $\begin{array}{l}\text { Agriculture and forestry support activities } \\
\text { (direct) }\end{array}$ \\
Direct energy costs & Power generation and supply** \\
Biological capital & Biological capital* \\
Chemical & Fertilizer manufacturing \\
Lime and biocides (pesticides, & Pesticide and other agricultural chemical \\
herbicides) & manufacturing \\
Irrigation & Water, sewage, and other systems \\
\hline
\end{tabular}

* Computed in FEBEF based on direct emissions.

** Power generation and supply used for algae, while terrestrial crops used diesel fuel factor computed internally.

\section{S4.8 EIO-LCA Energy Computations}

We used EIO-LCA model factors to estimate the direct and embedded energy use from the EIO-LCA model (Turhollow and Sokhansanj, 2007). We found the EIO-LCA energy use multipliers for eight categories of economic activity in the production of biomass feedstocks. The energy use multiplier for Direct Energy was computed internally in the FEBEF model. The Energy Use for the different categories of production was then calculated by multiplying the economic activity cost with the energy use multiplier. The Total Energy Use (TEU) for each crop was computed by summing all of the production categorical energy uses. The economic activity and the EIO-LCA model categories are the same as those used for GHG emissions and are shown in Table S2.

\section{S5. Primary Results Worksheet}

The Primary Results worksheet (PR tab) receives inputs from the PA worksheet and builds out fuel and GHG comparisons. Two performance metrics form the foundation of FEBEF model computations: WUE; the ratio of carbon captured to water transpired by a plant and RUE; the ratio of carbon captured to incident solar energy received by a plant. Multiplying WUE with growing-season rainfall and multiplying RUE with growingseason solar energy enables a first-order approximation of the maximum possible biomass accumulation on a water- or light-limited basis. These two maximum biomass accumulations are converted into MHYs by accounting for losses due to respiration, losses due to root exudates, and the fraction of biomass left in the field after harvest. The lower of the two MHYs is selected as the predicted yield. The exact calculations are described in detail below.

Maximum Annual Biomass at Theoretical Maximum RUE

The Maximum Annual Biomass Yield potential based on RUE $E_{\max }$ and PAR available was calculated in Equation 19, as shown below:

$\operatorname{MABTM}_{R U E}(M g /(h a \cdot a))=\frac{\operatorname{Annual} \operatorname{PAR}\left(\frac{W}{m^{2}}\right) \times R U E_{\text {max }}\left(\frac{\text { gbiomass }}{M J}\right)}{B E C\left(\frac{M J}{\text { gbiomass }}\right)}$

\section{Maximum Seasonal Biomass at Theoretical Maximum RUE}

The Maximum Seasonal Biomass Yield potential based on RUE $E_{\max }$ and seasonally available PAR was calculated in Equation 20.

$\operatorname{MSBTM}_{\text {RUE }}(M g /(h a \cdot a))=\operatorname{MABTM}_{\text {RUE }}(M g /(h a \cdot a)) \times$

Seasonal Fraction Solar Available )
(Eq. 20) 
Maximum Seasonal Biomass at Actual RUE

The Maximum Seasonal Biomass Yield potential based on RUE actual $_{\text {and }}$ seasonally available PAR was calculated in Equation 21, as shown below:

$\operatorname{MSBA}_{R U E}(M g /(h a \cdot a))=\operatorname{MSBTM}_{R U E}(M g /(h a \cdot a)) \times R U E R$

\section{MHY-Light Limited}

The Maximum Seasonal Biomass Yield potential based on RUE actual, $_{\text {, }}$ Seasonally available PAR and de-rated for carbon and harvest losses was calculated in Equation 22, as shown below:

$M H Y_{R U E}\left(M g /(h a \cdot a)=M S B A_{R U E}\left(M g /(h a \cdot a) \times h f_{T F C}\right.\right.$

\section{Maximum Annual Biomass at Theoretical Maximum WUE}

The Maximum Annual Biomass Yield potential based on $\mathrm{WUE}_{\max }$ and Annual Rainfall available was calculated in Equation 23, as shown below:

$\operatorname{MABTM}_{W U E}(\mathrm{Mg} /(\mathrm{ha} \cdot a)=$

Annual Total Rainfall $(\mathrm{cm}) \times W U E_{\max }\left(\frac{\text { gbiomass }}{\left.\mathrm{kgH}_{2} \mathrm{O}\right)} \times\left(\right.\right.$ Molecular Weight C/Molecular Weight $\left.\mathrm{CO}_{2}\right)$ Crop Carbon Content $\left(\frac{\mathrm{g}}{\mathrm{kg}}\right)$

\section{Maximum Seasonal Biomass at Theoretical Maximum WUE}

The Maximum Seasonal Biomass Yield potential based on $\mathrm{WUE}_{\max }$ and seasonally available PAR was calculated in Equation 24, as shown below:

$\operatorname{MSBTM}_{W U E}(\mathrm{Mg} /(\mathrm{ha} \cdot a))=\operatorname{MABTM}_{W U E}(\mathrm{Mg} /(\mathrm{ha} \cdot a)) \times$

Seasonal Fraction Water Available

\section{Maximum Seasonal Biomass at Actual WUE}

The Maximum Seasonal Biomass Yield potential based on $\mathrm{WUE}_{\text {actual }}$ and seasonally available rainfall was calculated in Equation 25, as shown below:

$\operatorname{MSBA}_{W U E}(M g /(h a \cdot a))=\operatorname{MSBTM}_{W U E} M g /(h a \cdot a) \times W U E R$

\section{MHY-Water Limited}

The Maximum Seasonal Biomass Yield potential based on WUE actual, Seasonally available rainfall and de-rated for carbon and harvest losses was calculated in Equation 26, as shown below:

$M H Y_{W U E}(M g /(h a \cdot a))=M S B A_{W U E}(M g /(h a \cdot a)) \times h f_{T F C}$

\section{Ratio of Max light to Max water Yields (RMHY)}

The ratio of MHYs from the water and light limited scenarios was calculated in Equation 27, as shown below:

$R M H Y=\frac{M H Y_{R U E}(M g /(h a \cdot a))}{M H Y_{W U E}(M g /(h a \cdot a))}$

$M H Y$

As mentioned above, the model feeds forward a predicted yield from either the $\mathrm{MHY}_{\mathrm{WUE}}$ or $\mathrm{MHA}_{\mathrm{UE}}$, whichever is lower.

\section{S5.1 Anticipated Yield in 2015 assuming historical yield improvements}

Assumption is made that yield improvements are smooth and constant from year to year. Yearly yield improvement data is based on literature. In the FEBEF model, we add one row with the yearly percentage improvement from the previous year so that we can calculate yield of any future year of interest.

\section{Gross Maximum Energy Yield}

The Gross Maximum Energy Yield $\left(\mathrm{MEY}_{\mathrm{G}}\right)$ was calculated by Equation 28, as shown below:

$M E Y_{G}(G J /(h a \cdot a))=M H Y(M g /(h a \cdot a)) \times B E C(M J / k g)$

\section{Net Maximum Energy Yield}

The Net Maximum Energy Yield as calculated by Equation 29 shown below:

$M E Y_{N}(G J /(h a \cdot a))=M E Y_{G}(G J /(h a \cdot a))-T E(G J /(h a \cdot a))$

$\mathrm{MEY}_{\mathrm{N}}$ was also reported in units of gallons gasoline equivalents (gge/(acre.a)).

Water Intensity Factor (Transpired for Biomass vs. Fuel)

The ratio of water use on the basis of that transpired by the crop to fuel potential $\left(\mathrm{MEY}_{\mathrm{gn}}\right.$ in terms of gasoline equivalent units) was reported in units of gal $\mathrm{H}_{2} \mathrm{O} /$ gge as shown below in Equation 30:

$W I F_{T B}=\frac{M H Y(M g / h a \cdot a))}{W U E_{\text {actual }}\left(\frac{g b i o m a s s}{k g H_{2} O}\right)} \times \frac{1}{\left.M E Y_{n}(G J / h a \cdot a)\right)}$

\section{S5.2 Net eutrophication potential ( $N$ and $P$ discharges) for all crops}

The net eutrophication analysis is based on DAYCENT simulation of corn at eight sites in the Midwest. We have taken raw data from Kim et al. (2009) for yield, fertilization, and eutrophication. They express eutrophication on the basis of $\mathrm{g} \mathrm{PO}_{4}{ }^{-} \mathrm{eq} / \mathrm{kg}$ grain basis. We have then computed eutrophication potential on an areal basis. We have also computed $\mathrm{N}$ applied per unit grain produced, total $\mathrm{N}$ and $\mathrm{P}$ applied per unit area, and $\mathrm{N}+\mathrm{P}$ per unit grain. Each of these has been correlated on total eutrophication per unit grain produced and per unit area. The highest correlation is between N/grain and eutrophication per unit grain (linear $\mathrm{r}=$ $\left.0.97, r^{2}=0.95\right)$. Fitting this to a logarithmic curve gives $r^{2}=0.976$, so this expression was used. The equation $2.6602 \ln (\mathrm{x})+11.836$ is then used with the FEBEF model data on N/grain to compute the eutrophication potential per unit grain for the grain scenario.

Energy Return on Investment (EROI)

The EROI was calculated based on $\mathrm{MEY}_{\mathrm{G}}$ and TEU. Equation 31 shown below was used for the calculation:

$E R O I=\frac{M E Y_{G}(G J /(h a \cdot a))}{T E(G J /(h a \cdot a))}$

\section{Total Production Cost (TPC)}

The total cost of production was calculated and reported in terms of US $\$ /$ ha and US \$/ac. The calculation used is shown in Equation 32 below:

TPC (US \$/(ha a a))

(Eq. 32)

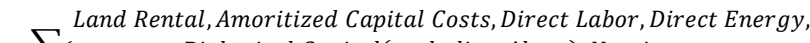

$=\sum(\quad$ Biological Capital (excluding Algae $)$, Nutrients, $)$ Biocides, and Irrigation (Algae only) 


\section{Biomass Production Cost (BPC)}

The biomass production cost was calculated and reported in terms as shown in Equation 33 below:

$B P C\left(\frac{U S \$}{M g}\right)=\frac{T P C(U S \$ /(h a \cdot a))}{M H Y(M g /(h a \cdot a))}$

BPC was also reported in US \$/ton.

\section{Energy Cost $(E C)$}

The energy cost, which accounts for production up to the harvesting of the biomass, was calculated as shown in Equation 34 below:

$E C\left(\frac{U S \$}{G J}\right)=\frac{T P C(U S \$ /(\mathrm{h} a \cdot a))}{\left.M E Y_{G}(G J / \mathrm{h} a \cdot a)\right)}$

EC was also reported in terms of US \$/gge.

\section{Carbon Intensity of Energy Source (CIES)}

The global climate change potential intensity was estimated by calculating the ratio of total GHG to net energy produced for each crop. The CIES was calculated as shown in Equation 35 below:

$\operatorname{CIES}\left(M T \mathrm{CO}_{2}\right.$ eq $\left./(h a \cdot a)\right)=\frac{G H G T\left(k g C O_{2} /(h a \cdot a)\right)}{M E Y_{N}(G J /(h a \cdot a))}$

\section{Ratio of MHY to Best Reported Yields (BRY)}

In order to place the MHY predicted by FEBEF in a realistic context, we found BRYs in the literature (for the different crops under similar climatic conditions and on plots greater than 10 ha when possible) and computed a ratio (RY) and reported as a percentage as shown below in Equation 36:

$R Y=\frac{M H Y(M g /(h a \cdot a))}{B R Y(M g /(h a \cdot a))}$

\section{Transportation Fuel Energy Out (TFEO)}

The TFEO was based on algal oil content, Transesterification Efficiency (mass biodiesel/mass raw oil), and the energy content of biodiesel (ECB) from microalgae, $41 \mathrm{MJ} / \mathrm{kg}$ (ref), as shown in Equation 37:

TFEO $\left(\frac{G J_{\text {out }}}{\text { dry Mg biomass }}\right)=$ AOC $\left(\frac{\mathrm{kg} \text { oil }}{\mathrm{kg} \text { biomass }}\right) \times$ Transesterification Efficiency $\times$ $\operatorname{ECB}\left(\frac{G J}{M g}\right)$

\section{Total Fuel Energy Yield (TFEY)}

The TFEY was based on TFEO and the MHY as shown in Equation 38:

$\operatorname{TFEY}\left(\frac{G J_{\text {out }}}{(\text { ha } \cdot a)}\right)=\operatorname{TFEO}\left(\frac{G_{\text {out }}}{\text { dryMg biomass }}\right) \times M H Y\left(\frac{\text { dry Mg biomass }}{(\text { ha } a)}\right)$

\section{Co-Product Credit}

The Co-Product Credit was assumed to be the energy content in the de-oiled algal biomass sold as feed as shown in Equation 39:

$C P C\left(\frac{G J_{\text {out }}}{\text { Lbiodiesel }}\right)=\frac{\text { Deoiled Algae Biomass }\left(\frac{G J}{\text { MgBiomass }}\right)}{\text { Biodiesel Yield }\left(\frac{L}{\text { Mg Biomass }}\right)}$

\section{Indirect GHG Emissions}

The Indirect GHG Emissions associated with the conversion of corn, corn stover, Switchgrass, and Miscanthus to ethanol and algal biomass to biodiesel were estimated using custom GHG EIO-LCA Multipliers, literature based estimates for the cost of conversion (CC), and the TFEY as shown in Equation 40. The custom GHG multiplier for ethanol and biodiesel conversion were built using an economic impact studies of ethanol and of biodiesel (Urbanchuk, 2007) and the EIO-LCA custom model tool (Carnegie Mellon University Green Design Institute, 2010). Specifically, the purchases (US \$/a) made by the ethanol and biodiesel industry from 11 sectors of the economy were used as inputs in the EIOLCA custom model tool to compute the associated GHG output for each sector given those expenditures.

$I_{G H G}\left(\frac{M g \mathrm{CO}_{2} e}{(h a \cdot a)}\right)=G H G_{E I O}\left(\frac{M g \mathrm{CO}_{2} e}{U S \$}\right) \times C C\left(\frac{U S \$}{G J_{\text {out }}}\right) \times \operatorname{TFEY}\left(\frac{G J_{\text {out }}}{(\text { ha } \cdot a)}\right)$

\section{Carbon Intensity of Fuel Energy Source (CIFES)}

The sum of the conversion and production GHG direct and indirect emissions term gave the total GHG on an areal basis. The CIFES was calculated by using the GHG total (GHGT; areal basis) and TEFY as shown in Equation 41:

$\operatorname{CIFES}\left(\frac{\mathrm{kg} \mathrm{CO}_{2} e}{\mathrm{GJ}_{\text {out }}}\right)=\frac{G H G T\left(\frac{M T C \mathrm{O}_{2}}{(\mathrm{haa} \cdot \mathrm{a})}\right)}{\operatorname{TEFY}\left(\frac{G J_{\text {out }}}{(\text { ha:a })}\right)} \times 1000(\mathrm{~kg} / \mathrm{Mg})$

(Eq. 41)

\section{Indirect Energy for Conversion}

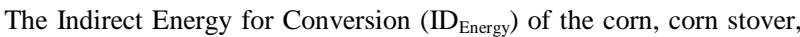
Switchgrass, and Miscanthus to ethanol and algal biomass to biodiesel were estimated using custom Conversion Energy EIO-LCA Multipliers, literature based estimates for the cost of conversion, and the TFEY as shown in Equation 42. The custom Conversion Energy multiplier was built using an economic impact studies of ethanol and biodiesel (Urbanchuk 2007) and the EIO-LCA custom model tool (Carnegie Mellon University Green Design Institute, 2010). Specifically, the purchases (US \$/a) made by the ethanol and biodiesel industry from 11 sectors of the economy were used as inputs in the EIO-LCA custom model tool to compute the associated energy expended by each sector given those expenditures.

$I D_{\text {Energy }}\left(\frac{G J}{(h a \cdot a)}\right)=$ Conversion Energy $y_{E I O}\left(\frac{G J}{U S \$}\right) \times$ Cost of Conversion $\left(\frac{U S \$}{G J_{\text {out }}}\right) \times T F E Y\left(\frac{G J_{\text {out }}}{(\text { ha.a })}\right)$

\section{Maximum Fuel Energy Yield-Net Converted}

The Maximum Fuel Energy Yield-Net Converted $\left(\mathrm{MFEY}_{\mathrm{NC}}\right)$ for producing and converting algal biomass to biodiesel was estimated using TFEY, TEU (direct and indirect) for Production (TEUP), and TEU for Conversion (TEUC) as shown in Equation 43, where all terms are in units of GJ ha $\mathrm{h}^{-1} \mathrm{a}^{-1}$.

$M F E Y_{N C}=T F E Y-T E U P-T E U C$

\section{Maximum Fuel Energy Yield-Net Converted with Co-Product Credit}

The TFEY, TEUP, and TEUC with Co-Product Credit $\left(\right.$ TEUC $_{\mathrm{CPC}}$ ) were used to compute the $\mathrm{MFEY}_{\mathrm{NC}}$ with Co-Product Credit $\left(\mathrm{MFEY}_{\mathrm{NC}-\mathrm{CPC}}\right)$ for producing and converting algal biomass as shown in Equation 44, where all terms are in units of GJ/ha.a.

$M F E Y_{N C-C P C}=T F E Y-T E U P-T E U C_{C P C}$

(Eq. 44) 


\section{Energy Return on Investment (EROI)}

The TFEY and Total Energy Use for Production and Conversion (TEUPC) were used to compute the EROI as shown in Equation 45, where all terms are in units of $\mathrm{GJ} /$ ha.a.

$E R O I=\frac{T F E Y}{T E U P C}$

\section{EROI with Co-Product Credit}

The TFEY, CPC and Total Energy Use for Production and Conversion (TEUPC) were used to compute the EROI as shown in Equation 46, where all terms are in units of $\mathrm{GJ} / \mathrm{ha}$.a.

$E R O I_{C P C}=\frac{T F E Y+C P C}{T E U P C}$

(Eq. 46)

\section{Cost for Conversion of Fuel Energy Produced (CCFEP)}

The TFEY and CC were used to compute CCFEP as shown in Equation 47:

$\operatorname{CCFEP}\left(\frac{U S \$}{(h a \cdot a)}\right)=\operatorname{TFEY}\left(\frac{G J_{\text {out }}}{(h a \cdot a)}\right) \times$ Cost of Conversion $\left(\frac{U S \$}{G J}\right)$

\section{Total Cost for Fuel Energy Produced (TCFEP)}

The Total Cost for Production (TCP) and the CCFEP were used to compute TCFEP as shown below in Equation 48 where all terms are in units of US $\$ /($ ha $\cdot \mathrm{a})$.

$T C F E P=T C P+C C F E P$

(Eq. 48)

\section{Cost for Fuel Energy Produced (CFEP)}

The CCFEP and the TFEY were used to compute CFEP as shown in Equation 49:

$\operatorname{CFEP}\left(\frac{U S \$}{G J}\right)=\operatorname{CCFEP}\left(\frac{U S \$}{(h a \cdot a)}\right) / \operatorname{TFEY}\left(\frac{G J}{(h a \cdot a)}\right)$

\section{Total Energy Cost (TEC)}

The cost for all energy produced including fuel and co-product credits from production to conversion was estimated as shown in Equation 50:

$\operatorname{TEC}\left(\frac{U S \$}{G J_{\text {out }}}\right)=\operatorname{TCFEP}\left(\frac{U S \$}{(\text { ha a })}\right) /\left(\operatorname{TFEY}\left(\frac{\text { G Jout }_{\text {out }}}{(\text { ha:a })}\right)+C P C\left(\frac{G_{\text {Jout }}}{(\text { ha } a)}\right)\right)$

\section{References}

[1] Amos, B., Walters, D.T., 2006. Maize root biomass and net rhizodeposited carbon. Soil Sci. Soc. Am. J. 70(5), 1489-1503.

[2] Beale, C.V., Long, S.P., 1995. Can perennial C $_{4}$ grasses attain high efficiencies of radiant energy conversion in cool climates?. Plant, Cell Environ. 18(6), 641-650

[3] Benemann, J.R., Oswald, W.J., 1994. Systems and economic analysis of microalgae ponds for conversion of $\mathrm{CO}_{2}$ to biomass. Nasa Sti/recon Technical Rep. N. 95.

[4] Bolton, J.R., Hall, D.O., 1991. The maximum efficiency of photosynthesis. Photochem. Photobiol. 53(4), 545-548.

[5] Brown Robert, C., 2003. Biorenewable Resources: Engineering New Products from Agricultural.

[6] Bonifas, K.D., Walters, D.T., Cassman, K.G., Lindquist, J.L., 2005. Nitrogen supply affects root: shoot ratio in corn and velvetleaf (Abutilon theophrasti). Weed Sci. 53(5) 670-675.
[7] Carnegie Mellon University Green Design Institute, 2008 Economic input-output life cycle assessment. (EIO-LCA), US 1997 Industry Benchmark model.

[8] Cherubini, F., Jungmeier, G., 2010. LCA of a biorefinery concept producing bioethanol, bioenergy, and chemicals from switchgrass. Int. J. Life Cycle Assess. 15(1), 53-66.

[9] Chisti, Y., 2007. Biodiesel from microalgae. Biotechnol. Adv. 25(3), 294-306.

[10] City and County of Honolulu, HI. Board of Water Supply.

[11] City of Phoenix Water Rates, Effective July 1, 2010.

[12] City of Tucumcari. Quay Water Plan, 2004.

[13] Clarens, A.F., Resurreccion, E.P., White, M.A., Colosi, L.M., 2010 Environmental life cycle comparison of algae to other bioenergy feedstocks. Environ. Sci. Technol. 44(5), 1813-1819.

[14] Edwards, W., 2009. Iowa State Extension: Cash Rental Rates for Iowa. File C2-10.

[15] El Bassam, N., Huisman, W., 2001. Harvesting and storage of Miscanthus. Miscanthus for energy and fibre. 86-108.

[16] Energy Information Administration, 2010. Average retail price of electricity to ultimate customers by end-use sector, by state. Electric Power Monthly with data for April 2010.

[17] Frank, A.B., Berdahl, J.D., Hanson, J.D., Liebig, M.A., Johnson, H.A., 2004. Biomass and carbon partitioning in switchgrass. Crop Sci. 44(4), 1391-1396.

[18] Glassner, D.A., Hettenhaus, J.R., Schechinger, T.M., 1998. Corn stover collection project, BioEnergy'98: expanding BioEnergy partnerships. Madison, Wisconsin.

[19] Grima, E.M., Belarbi, E.H., Fernández, F.A., Medina, A.R., Chisti, Y., 2003. Recovery of microalgal biomass and metabolites: process options and economics. Biotechnol. Adv. 20(7-8), 491-515.

[20] Hallenbeck, P.C., Benemann, J.R. Biological hydrogen production; fundamentals and limiting processes. Int. J. Hydrog. Energy 27 (11 12), 1185-1193.

[21] Hase, R., Oikawa, H., Sasao, C., Morita, M., Watanabe, Y., 2000. Photosynthetic production of microalgal biomass in a raceway system under greenhouse conditions in Sendai city. J. Biosci. Bioeng. 89(2), 157-163.

[22] Hernandez-Ramirez, G., Brouder, S.M., Smith, D.R., Van Scoyoc, G.E., 2009. Greenhouse gas fluxes in an eastern corn belt soil: weather, nitrogen source, and rotation. J. Environ. Qual. 38(3), 841 854.

[23] Hoskinson, R.L., Karlen, D.L., Birrell, S.J., Radtke, C.W., Wilhelm, W.W., 2007. Engineering, nutrient removal, and feedstock conversion evaluations of four corn stover harvest scenarios. Biomass Bioenergy. 31(2-3), 126-136.

[24] http://www.weatherbase.com/weather/state.php3?c=US\&refer

[25] Huntley, M.E., Redalje, D.G., 2007. $\mathrm{CO}_{2}$ mitigation and renewable oil from photosynthetic microbes: a new appraisal. Mitigation Adapt. Strategies Global Change. 12(4), 573-608.

[26] New Mexico Electricity Rates and Consumption, industrial user rate.

[27] Johnson, J.M.F., Barbour, N.W., Weyers, S.L., 2007. Chemical composition of crop biomass impacts its decomposition. Soil Sci. Soc. Am. J. 71(1), 155-162.

[28] Kahle, P., Beuch, S., Boelcke, B., Leinweber, P., Schulten, H.R., 2001. Cropping of miscanthus in Central Europe: biomass production and influence on nutrients and soil organic matter. Eur. J. Agron. 15(3), 171-184.

[29] Kim, S., Dale, B.E., Jenkins, R., 2009. Life cycle assessment of corn grain and corn stover in the United States. Int. J. Life Cycle Assess. 14(2), 160-174

[30] Kiniry, J.R., Tischler, C.R., Van Esbroeck, G.A., 1999. Radiation use efficiency and leaf $\mathrm{CO}_{2}$ exchange for diverse $\mathrm{C}_{4}$ grasses. Biomass Bioenergy. 17(2), 95-112.

[31] Lemus, R., Brummer, E.C., Moore, K.J., Molstad, N.E., Burras, C.L., Barker, M.F., 2002. Biomass yield and quality of 20 switchgrass populations in southern Iowa, USA. Biomass Bioenergy. 23(6), 433-442.

[32] Linacre, E., 2018. Ratio of Lakes to Pan Evaporation. Accessed: $11 / 27 / 2018$. 
[33] Marion, W., Wilcox, S., 1995. Solar radiation data manual for buildings. National Renew. Energy Lab., Golden, CO (United States).

[34] McLaughlin, S.B., Samson, R., Bransby, D., Wiselogel, A., 1996. Evaluating physical, chemical, and energetic properties of perennial grasses as biofuels. In Proc. Bioenergy. 96, 1-8.

[35] Melis, A., Neidhardt, J., Benemann, J.R., 1998. Dunaliella salina (Chlorophyta) with small chlorophyll antenna sizes exhibit higher photosynthetic productivities and photon use efficiencies than normally pigmented cells. J. Appl. Phycol. 10(6), 515-525.

[36] Moiser, A.R., Halvorson, A.D., Peterson, G.A., Robertson, G.P., Sherrod, L., 2005. Measurement of net global warming potential in three agroecosystems. Nutr. Cycling Agroecosyst. 72(1), 67-76.

[37] Monti, A., Di Virgilio, N., Venturi, G., 2008. Mineral composition and ash content of six major energy crops. Biomass Bioenergy. 32(3), 216223.

[38] Neild, R.E., Newman, J.E., 1990. Growing season characteristics and requirements in the Corn Belt. Natl. Corn Handbk. 40.

[39] Nobel, P.S., 1991. Achievable productivities of certain CAM plants: basis for high values compared with $\mathrm{C}_{3}$ and $\mathrm{C}_{4}$ plants. New Phytol. 119(2), 183-205.

[40] Omonode, R.A., Vyn, T.J., Smith, D.R., Hegymegi, P., Gál, A., 2007. Soil carbon dioxide and methane fluxes from long-term tillage systems in continuous corn and corn-soybean rotations. Soil Tillage Res. 95(12), 182-195.

[41] Pordesimo, L.O., Hames, B.R., Sokhansanj, S., Edens, W.C., 2005. Variation in corn stover composition and energy content with crop maturity. Biomass Bioenergy. 28(4). 366-374.

[42] Rochette, P., Desjardins, R.L., Pattey, E., Lessard, R., 1996. Instantaneous measurement of radiation and water use efficiencies of a maize crop. Agron. J. 88(4), 627-635.

[43] Smeets, E.M., Lewandowski, I.M., Faaij, A.P., 2009. The economical and environmental performance of miscanthus and switchgrass production and supply chains in a European setting. Renew. Sust. Energy Rev. 13(6-7), 1230-1245.
[44] Taylor, D.K., Rank, D.R., Keiser, D.R., Smith, B.N., Criddle, R.S. Hansen, L.D., 1998. Modelling temperature effects on growthrespiration relations of maize. Plant, Cell Environ. 21(11), 11431151

[45] Tokuşoglu, Ö., Üunal, M.K., 2003. Biomass nutrient profiles of three microalgae: Spirulina platensis, Chlorella vulgaris, and Isochrisis galbana. J. Food Sci. 68(4), 1144-1148.

[46] Turhollow, A.F., Sokhansanj, S., 2007. Costs of harvesting, storing in a large pile, and transporting corn stover in a wet form. Appl. Eng. Agric. 23(4), 439-448.

[47] Urbanchuk, J.M., 2007. Economic Contribution of the Biodiesel Industry, Prepared for the National Biodiesel Board With Funding Support from the USDA Biodiesel Fuel Education Program.

[48] Vadas, P.A., Barnett, K.H., Undersand, D.J., 2008. Economics and energy of ethanol production from alfalfa, corn, and switchgrass in the Upper Midwest, USA. Bioenergy Res. 1(1), 44-55.

[49] Vogel, K.P., Brejda, J.J., Walters, D.T., Buxton, D.R., 2002. Switchgrass biomass production in the midwest USA. Agron. J. 94(3), 413-420.

[50] Wallace, H.A., 1923. Corn and Corn Growth. Braunworth and Co. USA.

[51] Wanga, W., Ohse, K., Liu, J., Mo, W., Oikawab, T., 2005. Contribution of root respiration to soil respiration in a $\mathrm{C}_{3} / \mathrm{C}_{4}$ mixed grassland. J. Biosci. 30(4), 507-514.

[52] Western Regional Climate Center: Historical Climate Data: Evaporation Station.

[53] Wolf, D.D., Fiske, D.A., 1995. Planting and managing switchgrass for forage, wildlife, and conservation. Virginia Cooperative Extension Publication 418-013.

[54] Zelibor, J.L., Romankiw, L., Hatcher, P.G., Colwell, R.R., 1988. Comparative analysis of the chemical composition of mixed and pure cultures of green algae and their decomposed residues by ${ }^{13} \mathrm{C}$ nuclear magnetic resonance spectroscopy. Appl. Environ. Microbiol. 54(4), 1051-1060. 